\title{
SURTO DE TOXOPLASMOSE EM UM SEMINARIO DE BRAGANÇA PAULISTA (ESTADO DE SÃO PAULO). ASPECTOS CLÍNICOS, SOROLÓGICOS E EPIDEMIOLÓGICOS ${ }^{(1)}$
}

\author{
Cecilia MAGALDI (2) \\ Henrique ELKIS (2) \\ Dino PATTOLI (3) \\ José Cavalcante de QUEIRÓZ (3) \\ Antonio Lauro COSCINA (4) \\ José Maria FERREIRA (2)
}

\begin{abstract}
Nove casos de toxoplasmose adquirida comprovada (forma linfoglandular), ocorridos em um Seminário de Bragança Paulista, motivaram uma investigação clínica e sorológica. De acôrdo com os dados assim obtidos, pelo menos 30 pessoas (em um total de 81) apresentavam toxoplasmose na ocasião. Ao todo, foram realizadas 314 reações de Sabin-Feldman e de imunofluorescência indireta. O inquérito sorológico pela prova do corante extendeu-se também a algumas espécies animais da localidade. Em vista das limitações relativas à investigação epidemiológica, foi possivel apenas a colocação de várias hipóteses, nada se podendo concluir quanto aos aspectos epidemiológicos do surto. Registrando, pela primeira vez, na literatura médica esta ocorrência, os autores alertam para a possibilidade dêstes surtos em instituições fechadas ou zona rural. Insistem na necessidade de pesquisas mais profundas, em situações similares, para o reconhecimento das fontes de infeç̧ão e mecanismos de transmissão, a despeito das dificuldades decorrentes dos escassos conhecimentos sôbre a história natural da toxoplasmose e do ciclo biológico do parasita.
\end{abstract}

\section{N T R O D UÇA O}

Em novembro de 1965, por solicitação do Dr. José Themistocles de Aguiar Tartari, foram internados na Clínica de Doenças Tropicais e Infectuosas da Faculdade de Mediciná da Universidade de São Paulo, 9 jovens seminaristas, procedentes da cidade de Bragança Paulista, a fim de que, com maiores recursos, fôsse in. vestigada a natureza da doença infeccio- sa que então apresentavam. Confirmada a toxoplasmose como etiologia do processo, iniciou-se uma investigação epidemiológica que se prolongou desde novembro de 1965 até agôsto de 1966, no local de procedência dos pacientes. De acôrdo com os dados obtidos, pelo menos 30 pessoas em um total de 81 indivíduos, em tôda a área estudada, foram acometidas pela to-

Recebido para publicação em 19-10-1967.

(1) Da Clínica de Doenças Tropicais e Infectuosas do Hospital das Clínicas da Faculdade de Medicina da USP; do Departamento de Parasitologia da Faculdade de Higiene e Saúde Pública da USP e do Serviço de Laboratório Clínico do Hospital do Servidor Público Estadual.

(2) Da Clínica de Doenças Tropicais e Infectuosas do Hospital das Clinicas da F.M.

(3) Do Departamento de Parasitologia da F.H.S.P.

(4) Do Hospital do Servidor Público Estadual. 
MAGALDI, C. et alii - Surto de toxoplasmose em um seminário de Bragança Paulista, SP. Aspectos clínicos, sorológicos. Rev. Saûde públ., S. Paulo, 1(2):141-171, dez. 1967.

xoplasmose quase sempre na forma linfoglandular, caracterizando-se, assim, um surto epidêmico que atingiu aquela comunidade, na qual até então nenhum caso similar fôra assinalado.

Embora nos últimos 10 anos, tenha-se realizado apreciável número de pesquisas sôbre vários aspectos da toxoplasmose e o conhecimento de suas diversas formas clínicas se encontre bastante difundido em certos ramos da Medicina, muitos pontos permanecem ainda obscuros, sobretudo no que respeita à epidemiologia desta protozoose (Araujo ${ }^{2}, 1964$; Beattie ${ }^{4}, 1959$; Hartley ${ }^{13}, 1966$ ).

Casos comprovados de toxoplasmose ocorrendo no mesmo grupamento familiar têm sido registrados, com certa freqüência, na literatura médica (Амato Neto, Rivetti, Malheiros Jr. ${ }^{1}$, 1967; BeverLey \& Beattie ${ }^{6}, 1958$; Silm ${ }^{25}, 1951$ ). Não encontramos, todavia, referências a surtos epidêmicos cujo agente etiológico fôsse indubitàvelmente identificado como Toxoplasma gondii. $\mathrm{Na}$ comunicação de SingH et alii ${ }^{27}$ (1965) relatando a ocorrência, em caráter epidêmico, de doença hemorrágica provocada por picada de carrapato, persistiu a suspeita de toxoplasmose, não tendo sido possivel aos autores comprovar essa etiologia.

$O$ interêsse que a toxoplasmose vem despertando nos dias atuais, a necessidade de conhecimentos mais amplos e profundos, a oportunidade que se nos apresentou de observar casos simultâneos, além da inexistência de registro semelhante ao dêste surto, constituem a nosso ver, motivos válidos para justificar a presente publicação ainda que tenhamos encontrado inúmeras dificuldades no decurso do trabalho e a seu término, reconhecido falhas relacionadas principalmente aos aspectos epidemiológicos.

Os dados obtidos incialmente já foram apresentados, como nota prévia, $\left({ }^{1}\right)$ no 63. Seminário do Instituto de Medicina Tropical de São Paulo, em 24 de março de 1966 e no $1 .^{\circ}$ Congresso Latino-Americano de Parasitologia, em Santiago do Chile, em janeiro de 1967.

\section{MATERIAL E MÉTODOS}

Seminaristas internados - Nove seminaristas, de côr branca, cuja idade variava de 12 a 22 anos ( 1 com 22 anos e 8 com 12 a 16 anos) e que residiam no Seminário Santo Agostinho, desde 9 meses até há 5 anos em relação ao início do surto, adoeceram mais ou menos sùbitamente, entre os dias 18 a 22 de outubro de 1965. O quadro clínico manifestado por todos consistiu em: febre, cefaléia, tonturas, astenia, dores musculares, linfa. denopatia generalizada e hepatoesplenomegalia moderada. Em 5 casos foi referida diarréia aquosa, nos primeiros dias. $\mathrm{Na}$ fase aguda da infecção permaneceram hospitalizados em Bragança Paulista, durante 12 dias, tendo sido tratados com cloranfenicol. Em 4 pacientes foi também empregada a prednisona.

Ao serem internados na Clínica de Doenças Tropicais e Infectuosas, com cêrca de 20 dias de doença, já estavam quase sem sintomas, mas apresentando, ao exame fí. sico, infartamento ganglionar difuso, fígado e baço palpáveis e a maioria dos ca. sos com elevação de temperatura, ainda que moderada e irregular.

A análise das curvas térmicas de tôda a evolução evidenciou que a febre, desde $o$ início da infecção, foi diária quase sempre do tipo remitente, às vêzes intermitente, com elevação vespertina, durante um período de tempo que variou de 6 a 32 dias. Para 3 casos o período de febre diária de $37^{\circ}, 7 \mathrm{C}$ a $39^{\circ}, 5 \mathrm{C}$ teve duração de 26,31 e 32 dias. $E$ para os outros 6 casos, a febre de $37^{\circ}, 5 \mathrm{C}$ a $39^{\circ}, 8 \mathrm{C}$ durou de 6 a 10 dias.

Após o período de febre diária, excluíndo-se um paciente, os 8 restantes passaram a apresentar picos febris irregulares de $37^{\circ}, 2 \mathrm{C}$ a $37^{\circ}, 8 \mathrm{C}$, durante 15 a 55 dias,

(1) Dados inéditos. 
MAGALDI, C. et alii - Surto de toxoplasmose em um seminário de Bragança Paulista, SP. Aspectos clínicos, sorológicos.. Rev. Saúde pübl., S. Paulo, 1(2):141-171, dez. 1967.

com intervalos de apirexia. O período de observação na enfermaria da Clínica de Doenças Tropicais e Infectuosas foi de 45 dias para 3 casos e de 40 dias para os outros 6 casos. A Tabela 1 expõe os sintomas e sinais apresentados pelos 9 pacientes.

Caracterização da área estudada - 0 Seminário Santo Agostinho situa-se no bairro Bom Retiro, no distrito sede do
Município de Bragança Paulista (Fig. 1), ocupando uma área de 90 alqueires. ${ }^{(1)}$ A sede do Município está localizada a $22^{\circ} 58^{\prime}$ de latitude sul e $46^{\circ} 32^{\prime}$ de longitude, distando, em linha reta, $88 \mathrm{~km}$ da Capital de São Paulo. A altitude é de $850 \mathrm{~m}$; o clima é quente e o inverno é menos sêco. A média da temperatura máxima é de $22^{\circ} \mathrm{C}$ e a da mínima é de $16^{\circ} \mathrm{C}$, com média compensada de $19,4^{\circ} \mathrm{C}$. A altura total das precipitações pluviais ao ano é de $1.368 \mathrm{~mm}$.

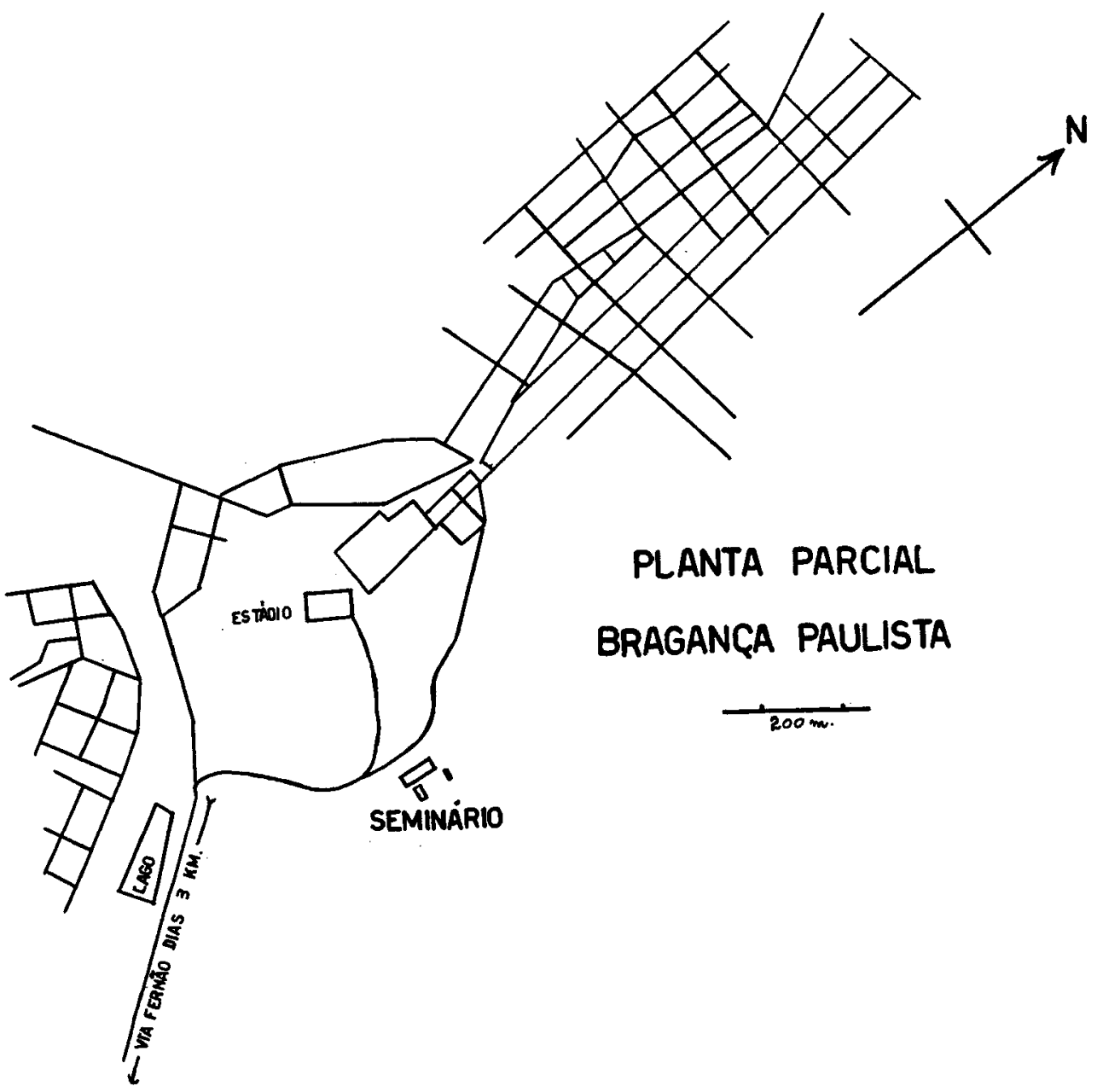

Fig. 1 - Seminário de Santo Agostinho (Bragança Paulista). Localização em planta parcial da cidade.

(1) Um alqueire igual a $24.200 \mathrm{~m}^{2}$. 
MAGALDI, C. et alii - Surto de toxoplasmose em um seminário de Bragança Paulista, SP. Aspectos clínicos, sorológicos.. Rev. Saúde públ., S. Paulo, 1(2):141-171, dez. 1967.

\section{T A B E L A 1}

Surto de toxoplasmose em um Seminário de Braganca Paulista. Sintomas e sinais em nove seminaristas internados na Clínica de Doencas Troplcais e Infectuosas da Faculdade de Medicina da Universidade de São Paulo.

\begin{tabular}{|c|c|c|}
\hline Sintomas e sinais & $\begin{array}{c}\text { N.o } \\
\text { de casos }\end{array}$ & $\%$ \\
\hline Febre & 9 & 100.0 \\
\hline Cefaléia & 7 & 77,8 \\
\hline Tonturas & 7 & 77,8 \\
\hline Diarréia & 5 & 55.6 \\
\hline Astenia & 4 & 44.5 \\
\hline Mialgias & 3 & 33.4 \\
\hline Calafrios & 3 & 33.4 \\
\hline Tosse sêca & 2 & 22,2 \\
\hline Epistaxe & 1 & 11,1 \\
\hline Eritema pruriginoso & 3 & 11,1 \\
\hline $\begin{array}{l}\text { Linfadenopatia } \\
\text { generalizada }\end{array}$ & $a$ & 100,0 \\
\hline $\begin{array}{l}\text { Esplenomegalia }(0,5 \text { a } \\
4 \mathrm{~cm})\end{array}$ & 9 & 100,0 \\
\hline $\begin{array}{l}\text { Hepatomegalia (2 a } \\
\quad 4 \mathrm{~cm} \text { ) }\end{array}$ & 8 & 88.9 \\
\hline
\end{tabular}

O Seminário localiza-se à entrada da sede do Município, em região com elevações e declives; há terras cultivadas com cana, café, hortaliças, pastos (capim gordura, soja perene, colonião), matas, eucaliptais, coleções de água e áreas construídas. (Fig. 2).

População do Seminário - Na época do surto e do inquérito, viviam no Seminário 5 padres, os outros 3 incluídos no estudo moravam no Colégio São Luís, mas estavam ligados ao Seminário em suas tarefas. Com exceção de um irmão leigo, todos eram de nacionalidade espanhola.

Os seminaristas eram ao todo 37 , procedentes do Município de Bragança Paulista ou regióes adjacentes, de outras cidade do interior do Estado de São Paulo ou de outros Estados (Goiás, Minas Gerais, Guanabara e Mato Grosso). Dos 28 seminaristas incluídos no inquérito, 13 ingressaram em 1965, sendo de 4 meses o tempo de permanência mais curto no Seminário. Quinze (15) cursavam aquêle estabelecimento há mais de 1 ano. Dos
8 padres, apenas 2 estavam no Seminário há 6 e 8 meses. Os demais viviam no local há mais de 2 anos.

Além de interrogatório e exame físico, foi efetuada em jejum colheita de sangue para provas sorológicas específicas de 28 seminaristas e 8 padres, um mês após o início do surto de toxoplasmose. A idade média dos alunos foi calculada em 14,5 e a dos padres em 38,7 anos. Todos os examinados, com exceção de um, eram de côr branca. Executando-se o aluno $16 \mathrm{~A}$ e - padre 7A, 8 indivíduos que apresentavam reações sorológicas positivas a 1:1024, forneceram uma segunda amostra de sangue para repetição das provas, cêrca de 3 meses após a primeira colheita. 0 alune $20 \mathrm{~A}$, embora tivesse reações negativas, repetiu as provas em 14-3-66, porque nessa data se apresentava febril e com esplenomegalia; o diagnóstico feito foi de recaída de malária por $P$. vivax. Foram também repetidas as reações em 3 alunos cujas provas sorológicas iniciais eram positivas em título 1:4000.

Serviam como funcionários sem residir na instituição 3 pessoas: 1 homem e 2 mulheres.

$\mathrm{Na}$ fazenda do Seminário residiam 41 pessoas, sendo 25 adultos e 16 crianças menores de 12 anos. Estes moradores constituiam 7 famílias ou agregados, assim distribuídos: família $S$ com 10 membros, família $C$ com 9, família $P$ com 7 , família $T$ com 6 , família OP com 5 e duas famílias $L$ e $M$ com 2 membros. Total de indivíduos em tôda área: 86 .

Trinta e seis (36) pessoas ligadas à fazenda do Seminário foram também fichadas, examinadas e forneceram amostras de sangue, em jejum, para as provas so. rológicas. Neste grupo, 13 eram menores de 12 anos.

$\mathrm{Na}$ primeira colheita, realizada cêrca de 1 mês após a eclosão do surto, compareceram 29 pessoas; das 7 restantes conseguimos colher material, apenas 4 meses depois. As reações foram repetidas em 10 individuos tanto com títulos iniciais de 


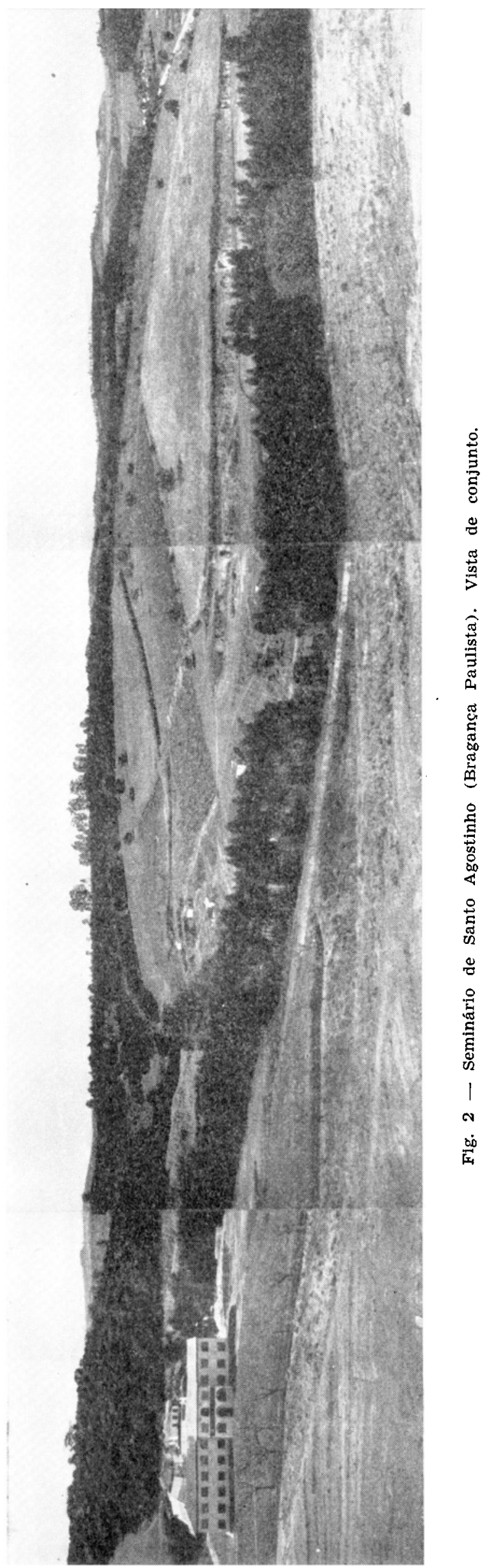


MAGALDI, C. et alii - Surto de toxoplasmose em um seminário de Braganca Paulista, SP. Aspectos clínicos, sorológicos. Rev. Saúde públ., S. Paulo, 1(2):141-171, dez. 1967.

$1: 1024$ como de 1:4000 ou mais; não pudemos realizar uma segunda colheita em 2 casos (25B e 31B), cujas reações primeiras foram, respectivamente, de 1:1024, e 1:4000, em 17-2-66.

\section{Condições de vida}

1 - Padres e Seminaristas - Habitaçấo - 0 edifício do Seminário Santo Agostinho é de construção recente e dotado de energia elétrica, água encanada e telefone. As instalações sanitárias consistem em 18 aparelhos (8 anexos ao dormitório) e 13 chuveiros ( 8 anexos ao dormitório), para uso dos alunos e padres (Fig. 3). Os seminaristas ocupam um único dormitório, onde há 40 camas, 8 janelas e 1 porta (Fig. 4). A sala de refeições é dotada de 4 mesas para 40 lugares. Há ainda 5 salas de aula, onde se distribue um número não superior a 40 estudantes e a capela.

Alimentação - Os produtos como hortaliças e legumes provêm da horta local; o leite de vaca, ordenhado de modo rudimentar, é consumido pelos padres, enquan. to os alunos recebem leite em pó. A carne de vaca vem, quase sempre, do mata- douro da fazenda onde não há instalações e condiçöes de higiene adequadas; a carne de carneiro, por outro lado, é de pouco consumo atualmente, tendo sido fornecida com maior regularidade em anos anteriores ao surto. Raramente se consome carne de porco. Os sub-produtos da carne são adquiridos na cidade de Bragança, assim como peixes de mar, que são servidos uma vez por semana. Peixes de água doce, inclusive pescados na lagoa da fazenda, são comidos esporàdicamente. $O s$ ovos provêm da fazenda e de granjas do $\mathrm{Mu}$ nicípio e são servidos fritos e cozidos, não havendo indicação de seu consumo em estado natural. A carne é apresentada assada, frita ou cozida e a informação de que os alunos não costumam comer carne crua ou mal passada foi quase unânime. Vez por outra era servido caldo de cana; alguns dias antes da eclosão da doença, os alunos foram tomar caldo de cana em casa de uma família da colonia, em cujo canavial localizado nos fundos da casa, alguns membros dessa família costumam fazer suas necessidads fisiológicas.

Agua - A água de abastecimento do Seminário é tratada (clorada), vem da cidade, fica depositada em caixa nova

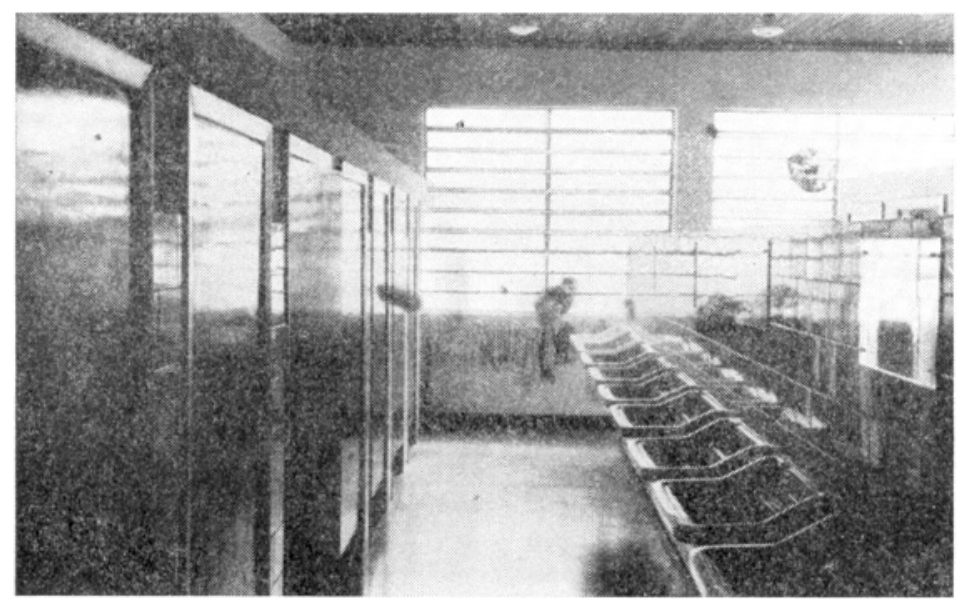

Fig. 3 - Seminário de Santo Agostinho (Bragança Paulista). Instalaçōes sanitárias. 
MAGALDr, C. et alii - Surto de toxoplasmose em um seminário de Bragança Paulista, SP. Aspectos clínicos, sorológicos. Rev. Saúde públ., S. Paulo, 1(2):141-171, dez. 1967.

adequada e serve às dependências da cozinha, copa e banheiros. A água do lago e da piscina, entre os quais há intercomunicação, não é potável. Além da água de abastecimento citada, há cêrca de 10 bicas ou nascentes, quase tôdas com água poluída e segundo as informaçōes de um padre, era costume servirem-se os alunos e moradores da colonia da água de uma das bicas perto do estábulo, onde as vacas e ovelhas também bebem (Fig. $5)$.

Esgotos - Existem duas fossas sépticas de grande capacidade, sem vazamento. Os sanitários são providos de sistema hi. dráulico moderno.

Atividades e hábitos - Os padres têm função administrativa e didática. Os seminaristas recebem aulas do curso de admissão e das 4 séries ginasiais pela manhã, nas dependências do Colégio São Luís, situado a menos de $1 \mathrm{~km}$ do Seminário, onde à tarde, há aulas de latim, instrução religiosa e recreação. A par dessas atividades há tarefas de limpeza interna, (incluindo os banheiros) e prática de esportes. Costumam fazer excursões aos arredores. Em 28-8-65 (50 dias antes do surto), foram todos a Perdões
(Municipio de Atibaia), onde jogaram futebol, nadaram no rio Atibaia (todos menos 3 dos seminaristas que adoeceram) e comeram salame do frigorífico de Bragança. Em 10-10-65, o passeio foi em uma estrada próxima ao trevo da rodovia Fernão Dias, junto à entrada de Bragança. Em 17-10-65, foram a Coquinhos, localidade que dista $500 \mathrm{~m}$ do trevo mencionado. Finalmente, um dia antes de cairem doentes também andaram pela mata da fazenda (Fig. 2), onde beberam água de brejo que é utilizada por animais. 0 contato com cães, carneiros $\mathrm{e}$ coelhos tem sido eventual. Um dos alunos (.$^{\circ} 34 \mathrm{~A}$ ) era encarregado de cuidar dos coelhos, que na ocasião eram em número de 19.

Em resumo, os seminaristas mantém atividades e práticas em comum, dormindo em um único aposento, ocupando os mesmos banheiros, salas de aula e refeitório e banhando-se nas mesmas coleçōes de água. É importante assinalar que a grande maioria dos alunos procede da zona rural, vivendo em fazendas de gado onde tiveram, portanto, anterior contato com diversas espécies de animais domésticos.

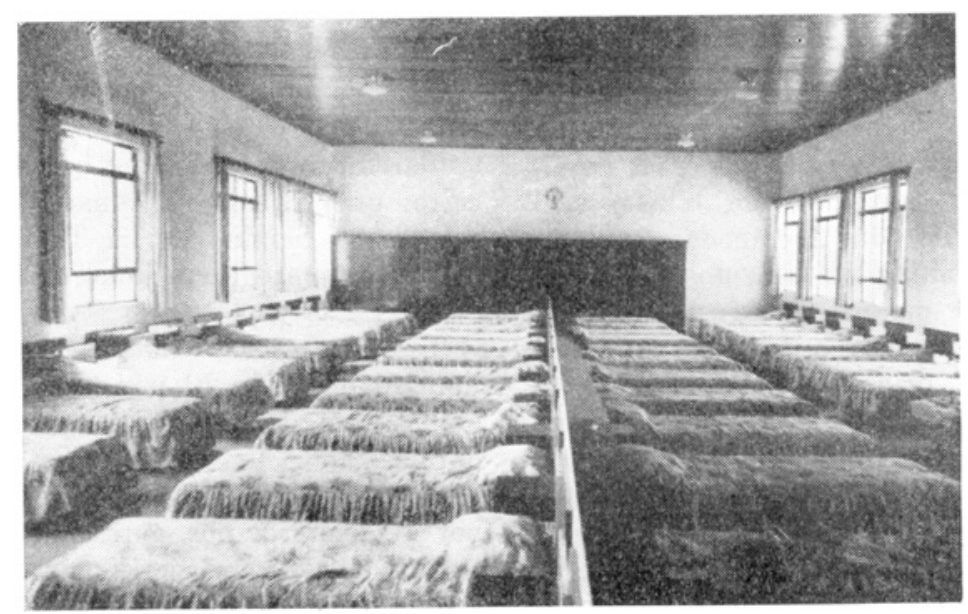

Fig. 4 - Seminário de Santo Agostinho (Bragança Paulista). Dormitório dos seminaristas. 
MAGALDI, C. et alii - Surto de toxoplasmose em um seminário de Bragança Paulista, SP. Aspectos clínicos, sorológicos. Rev. Sauide públ., S. Paulo, 1(2):141-171, dez, 1967.

Com referência ao Colégio São Luís, 105 alunos cursavam aquêle estabelecimento de ensino em 1965, não tendo havido nenhum caso clínico de toxoplasmo. se. Em 7 alunos foi levantada suspeita dessa infecção; na realidade 3 eram portadores de parotidite epidêmica e nos outros 4 , as queixas vagas foram atribuídas a processo gripal, sendo negativos os resultados do teste do corante e da imunofluorescência para toxoplasmose.

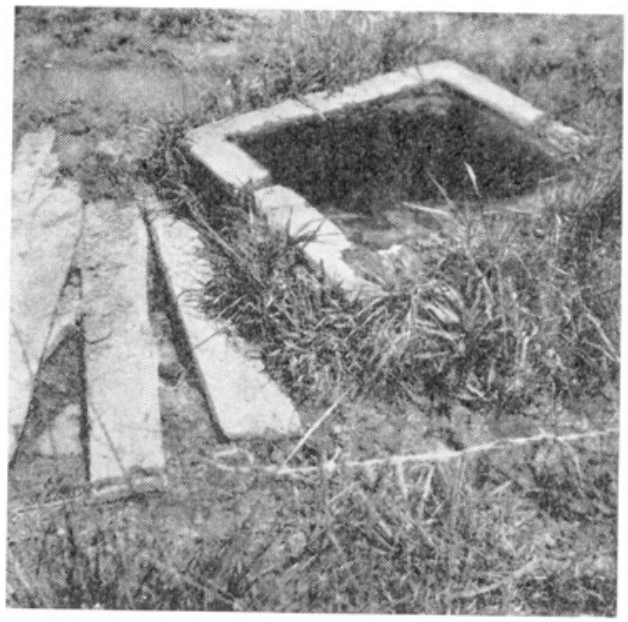

Fig. 5 - Seminário de Santo Agostinho (Bragança Paulista). Coleção de água poluida junto ao estábulo

2 - Colonos da Fazenda - Habitação - As 7 famílias que residiam na área do Seminário viviam em casas de alvenaria, com cobertura de telhas, sem fôrro, em geral com 2 cômodos, com piso de terra batida ou cimento, sem água encanada e a maioria sem instalação elétrica. Excluíndo-se a família do administrador de origem espanhola, que aí vive desde fevereiro de 1965 , as demais famílias moravam na fazenda há mais de 3 anos e são originárias do interior do Estado de São Paulo.

Alimentação - É deficiente sobretudo no tocante à qualidade $\mathrm{e}$ ao valor proteico dos alimentos, pois mesmo carne, leite e peixe de procedência interna são consumidos muito raramente.

Agua e Esgotos - Com exceção de uma família que recebe água encanada em casa, as demais se servem de água de nascente e afloramento, a qual recebe enxurrada da zona mais alta da fazenda, de mistura com águas servidas, que vêm dos estábulos e pocilgas. A água é bebida sem filtração ou fervura e é utilizada também para lavagem de utensílios, roupa, banho, etc. Quanto ao destino dos excreta, não há qualquer tipo de sistema de esgotos, sendo hábito evacuar diretamente no solo, entre matas ou canaviais.

Atividades e hábitos - Vinte e cinco (25) adultos, dentre os 41 residentes na fazenda, ocupavam-se em serviços de limpeza, manutenção, lavoura e pecuária. Quase tôdas as famílias criavam galinhas e possuiam cães e gatos. $\mathrm{Na}$ família $\mathrm{T}$, um menino de 13 anos cuidava das ovelhas. Possuia dois cães que foram mortos por parecerem raivosos, um dêles "Duque" tendo sido anteriormente sangrado para exame.

A situação sócio-econômica dos colonos é precária: além de não terem alimentação e condições sanitárias adequadas, andam sem calçado e sofrem de verminose. Poucos se alfabetizaram.

Dos 3 empregados do Seminário, 2 trabalhavam na copa e na cozinha, além de cuidarem do dormitório e costura. 0 terceiro, que trabalhava como cozinheiro e residia no Seminário, há 1 ano e meio, deixou o emprêgo em janeiro de 1966.

3 - Animars - Cães - Existiam em número de 15 a 20 por tôda a fazenda, alguns sem dono. Segundo informações obtidas, antes do surto, 3 cães morreram doentes. Um dêles vinha sendo tratado por veterinário, por apresentar paralisia. Outros dois foram sacrificados por terem convulsōes, secreção ocular e salivação abundante. Depois de ter sido iniciada a presente investigação, o cão "Dique", da 
MAGALDI, C. et alii - Surto de toxoplasmose em um seminário de Braganca Paulista, SP. Aspectos clínicos, sorológicos. Rev. Saúde pübl., S. Paulo, 1(2):141-171, dez. 1967.

família $T$, foi morto por parecer raivoso e, mais recentemente, em fevereiro de 1966 , o cão "Duque" que guardava as ovelhas e cuja reação de Sabin-Feldman poi positiva a 1:4000, também foi sacrificado por ter apresentado agitação. Nenhum dêles foi examinado.

Roedores - Há um número extremamente grande de ratos, tanto nos estábulos, celeiros e hortas, como dentro do edifício do Seminário, incluíndo a cozinha.

Coelhos - A criação de coelhos constava de 19 exemplares, todos aparentemente sadios. Durante nosso estudo, fomos informados de que morreram 2, um prematuro e outro adulto que se mostrou doente.

Suinos - Eram em número de 21, criados em pocilgas fechadas e sem água corrente. Não se apresentavam doentes. (Fig. 6A).

Bovinos - Existiam aproximadamente 60 bois de corte e 5 vacas leiteiras.
Ovinos - 0 rebanho de ovelhas e car. neiros constava de cêrca de 70 cabeças. Ultimamente, perderam-se numerosas ovelhas, com fraqueza intensa, diarréia e sem capacidade de reprodução. Em 10-2-66, foi encaminhado 1 carneiro para o Instituto Biológico de São Paulo, para exame. Posteriormente, foi autopsiado outro exemplar, verificando-se apenas verminose maciça. Com o tratamento anti-helmíntico instituído, o rebanho começou a ser recuperado. (Fig. 6B).

Aves - Nẫo havia criação de pombas ou pássaros de gaiola. Aves campestres, comuns no interior do Estado, eram alí encontradiças.

Artrópodes - Além de enorme quantidade de moscas junto à lavandaria, cozinha e estábulos, foi referida a existência de baratas, pulgas, carrapatos e reduvideos, êstes vivendo principalmente nas "barbas de bode", não longe do edifício do Seminário.

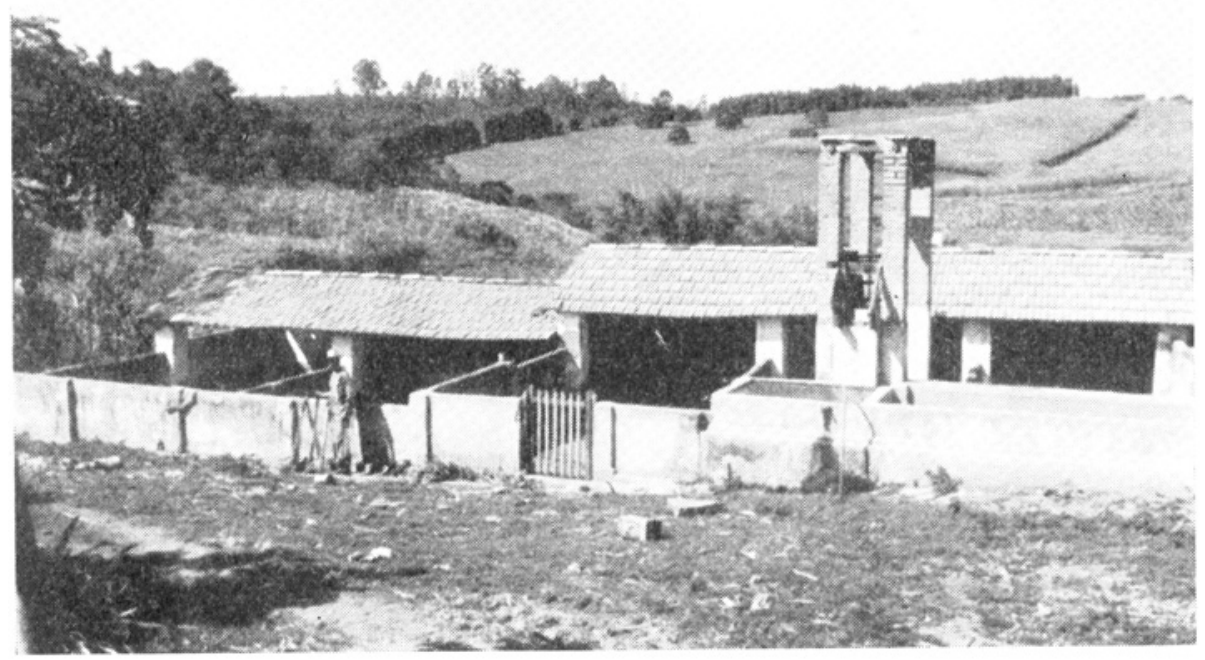

Fig. 6A - Seminário de Santo Agostinho (Braganca Paulista). Pocilgas. 
MAGALDI, C. et alii - Surto de toxoplasmose em um seminário de Bragança Paulista, Sí. Aspectos clínicos, sorológicos. Rev. Saúde públ., S. Paulo, 1(2):141-171, dez. 1967.

As reações sorológicas, para o diagnóstico de toxoplasmose realizadas com cada amostra de sangue coletado, consistiram na prova do corante e na reação de imunofluorescência indireta. Os soros obtidos por centrifugação adequada, após a retração do coágulo, foram congelados $\mathrm{a}-20^{\circ} \mathrm{C}$. Antes de se iniciarem as reações, os soros foram inativados a $56^{\circ} \mathrm{C}$, durante 30 minutos, e depois diluídos em solução de cloreto de sódio a $0,85 \%$. As diluições praticadas foram $1: 16,1: 64$, $1: 128,1: 256,1: 1024,1: 4000,1: 8000$, $1: 16000,1: 32000,1: 64000$, etc.

0 método empregado para a primeira reação foi o mesmo descrito por S $\mathrm{ABIN} \&$ Feldman ${ }^{23}$ (1948), sem modificações, usando-se toxoplasmas da cepa $M$.

Para a reação de imunofluorescência indireta foi adotada a técnica de KELEN, Ayllon-Cleinol, Labzoffsiry ${ }^{17}$ (1962), com algumas alterações introduzidas por Camargo $^{7}$ (1966). Foi utilizada a mesma cepa citada è sôro anti-globulina humana conjugado ao isotiocianato de fluo- resceina produzido pela "Silvana $\mathrm{Co}$ ", diluído a 1:40.

A leitura foi feita mediante microscó. pio "Zeiss" binocular, com objetiva de imersão $100 x$, diafragma iris, oculares $10 x$, campo escuro e condensador cardióide. A fonte de iluminação foi constituída por lâmpada $\mathrm{HBO}-200$, filtro excitador BG 12 de $3 \mathrm{~mm}$ e filtro barreira . $^{\circ}$ 50 "Zeiss". A fim de facilitar a leitura das reações foi empregada coloração de contraste pelo azul de Evans, segundo descriação de Nichols \& McComb ${ }^{19}$ (1962).

A inoculação de macerado de gânglio linfático no peritôneo de camundongos obedeceu, em linhas gerais, à técnica habitual, sem introdução de corticoesteróides (Jones et alii ${ }^{16}, 1958$ ). Imediatamente após sua ressecção, o gânglio foi colocado em solução fisiológica, em baixa temperatura e remetido ao laboratório.

Para as fezes, a técnica consistiu no seguinte: suspensão de, aproximadamente, 1 parte de fezes em 10 partes de solução de $\mathrm{ClNa}$ a $0,85 \%$, contendo 1.000 unidades de penicilina e 1.000 microgramas

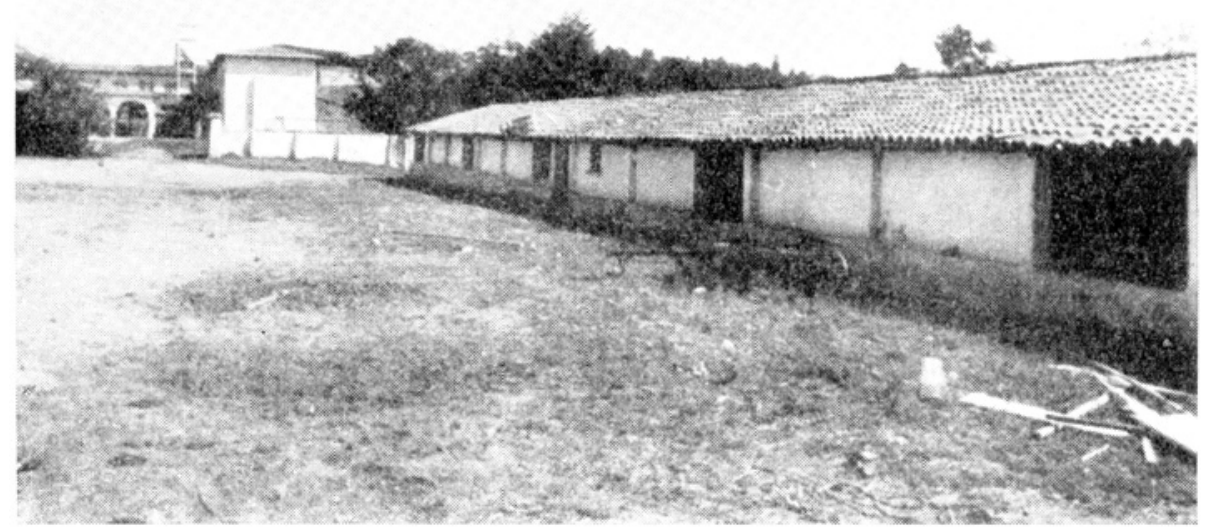

Fig. 6B - Seminário de Santo Agostinho (Bragança Paulista). Abrigo de carneiros. 
MAGALDI, C. et alii - Surto de toxoplasmose em um seminário de Bragança Paulista, SP. Aspectos clínicos, sorológicos. Rev. Saúde públ., S. Paulo, 1(2):141-171, dez. 1967.

de sulfato de estreptomicina por $\mathrm{ml}$. Um (1) $\mathrm{ml}$ de suspensão foi injetado intraperitonealmente em 3 camundongos. No quarto dia da inoculação os animais foram anestesiados, sendo então injetados $2 \mathrm{ml}$ de solução salina fisiológica conten. do os antibióticos, sendo feita a passagem para novos camundongos. Os animais da primeira inoculação foram observados ainda durante 10 dias e, no caso de se apresentarem negativos, foram sacrificados. Os camundongos inoculados na primeira passagem foram observados por mais uma semana, finda a qual foi feita a coleta do exsudato peritoneal com uma segunda passagem para camundongos. Os animais inoculados na primeira e segunda passagens foram observados por mais uma semana sendo feita nova coleta e exame do material peritoneal. Confirmada a negatividade, os mesmos foram sacrificados, retirados os cérebros e feito um triturado em solução salina fisiológica com antibióticos, seguida de nova inoculação intraperitoneal de $1 \mathrm{ml}$ da suspensão em 3 camundongos. Êstes animais foram observados a intervalos de 4 dias, quando foi retirado o material peritoneal. Mantendo-se negativa a pesquisa de toxoplasmas ao fim de 10 dias, os animais foram sacrificados e considerada negativa a pesquisa para aquela amostra.

Fêz-se também inoculação com uma suspensão de triturado de fígado, baço e cérebro obtidos de um exemplar de Rattus rattus rattus. Outra suspensão foi feita usando-se o conteúdo intestinal do animal. Foi adotada a mesma técnica de inoculação anteriormente descrita para as amostras de fezes.

\section{RESULTADOS}

Seminaristas internados - Os nove seminaristas foram submetidos a diversos exames subsidiários cujos resultados, enunciados de modo global e sintético, são os seguintes: a) hemograma - anemia moderada em 6 casos, leucocitose (10.500 a 11.200 leucocitos $/ \mathrm{mm} 3$ ) em 6 casos, sem neutrofilía, com desvio à esquerda em 6 casos, linfocitose em todos, com linfocitos atípicos (em 5 casos - 45 a $65 \%$ de linfocitos, em 4 casos - 39 a $41 \%$ ), monocitose em 5 pacientes (7 a $11 \%)$, eosinofilia em 4 casos (10 a $16 \%)$; b) dosagem da transaminase glutâmico-oxalacética - em 7 casos, entre 45 e $72 \mathrm{u} / \mathrm{ml}$ de sôro e em 2 casos foi normal $(22$ a $33 \mathrm{u} / \mathrm{ml})$; c) dosagem de proteinas séricas e fraçôes - sòmente ligeira elevação das globulinas em 6 casos; d) hemossedimentação - em 7 casos foi elevada entre 15 e $39 \mathrm{~mm}$ na 1 . $^{\text {a hora }}$ (normal para os casos entre 6 e $12 \mathrm{~mm}$ ); e) provas de turvação e floculação do ti$\mathrm{mol}$, realizadas em 2 casos apenas, revelaram turvação 6,3 e 7,9 u e flocula. ção $++\mathrm{e}+++$ respectivamente; f) exame parasitológico de fezes (pelo método de Faust \& col.) - positivo em 7 casos, com ancilostomíase 6 casos, ascaridíase 2 casos, tricocefalíase 1 caso e giardíase 2 casos.

A radiografia de torax, assim como o exame de fundo de ôlho, nada revelou de anormal, em todos os 9 seminaristas.

Quanto ao eletrocardiograma, o traçado foi normal em 5 alunos; em 4 foram assinalados sinais de miocardiopatia, assim distribuídos: em 3 havia alterações da repolarização ventricular, em 2 , sobrecarga do ventrículo $\mathrm{E}$, em 1 , sobrecarga da aurícula e do ventrículo $E$ e em outro arritmia sinusal (Dr. Domingos Alves Meira (1) . Não foi possivel, posteriormente, uma reavaliação das condições do miocárdio, através do E.C.G.

(1) Docente-livre da Clínica de Doenças Tropicais e Infectuosas do Hospital das Clínicas da FMUSP. 
MAGALDr, C. et alii - Surto de toxoplasmose em um seminário de Bragança Paulista, SP. Aspectos clínicos, sorológicos. Rev. Saúde públ., S. Paulo, 1(2):141-171, dez. 1967.

Em relação às provas sorológicas específicas, reação de Sabin-Feldman e de imunofluorescência indireta, os resultados obtidos, relacionados aos dias de doença, em 7 oportunidades em que as mesmas foram realizadas, encontram-se na Tabela 2.

A observação dos dados da Tabela 2, verificam-se os seguintes fatos: a) em todos os casos a prova do corante foi positiva em diluiçōes $\geq 1: 4000 ;$ b) nos casos 2 e 3 a positividade na diluição $\geq 1: 4000$, considerada como indicativa de doença em atividade, foi evidenciada tardiamente; c) o seguimento sorológico até ao redor do $140^{\circ}$ dia de doença mostrou que em 3 casos os títulos elevados no início cairam, em 2 aumentaram e em 4 houve oscilação de queda e ascensão durante o período; d) os resultados das duas provas foram quase sempre concordantes, havendo no máximo diferença de apenas um tubo.

Nos casos 1, 3 e 6 a inoculação de gânglios em camungondos adultos, via intraperitoneal, examinados após 10 dias, no Departamento de Parasitologia da F. M. U. S. P., foi positiva para toxoplasmose.

Os alunos foram submetidos a tratamento com sulfadiazina na dose de $6,0 \mathrm{~g}$ diárias e daraprim 1 comp. de $25 \mathrm{mg}$ ao dia, durante 14 dias. Ao receberem alta, iniciaram terapêutica com espiramicina, na dose de $50 \mathrm{mg} / \mathrm{kg}$ de pêso, por dia, durante 10 dias. Durante a internação foi observada regressão lenta das dimensões dos gânglios, do fígado e do baço.

Padres e demais seminaristas - $\mathrm{Na}$ Tabela 3, estão registrados os dados clínicos e resultados das reações obtidos nesse grupo, cujos indivíduos estão numerados de IA a 36A, sendo padres os n. ${ }^{\circ}$ s $1 \mathrm{~A}$ a $8 \mathrm{~A}$.

Como se pode verificar, 2 padres e 8 seminaristas tiveram reações positivas a 1:1024 no $1 .^{\circ}$ exame e 3 alunos (n.os 34A, $35 \mathrm{~A}$ e 36A) apresentaram títulos de
1:4000, para o teste do corante e para reação de imunofluorescência iniciais. Os demais tiveram reaçōes positivas em título $\leq 1: 256$.

Apenas em 1 caso (n. $\left.{ }^{\circ} 27 \mathrm{~A}\right)$, dentre os que reagiram a $1: 1024$, o título se elevou no $2 .^{\circ}$ exame; nos outros, os títulos foram mais baixos. Em relação aos 3 casos positivos a 1:4000, o título se manteve até 3 meses depois em um único seminarista $\left(n .^{\circ} 35 \mathrm{~A}\right)$, tendo ocorrido nítida queda nos 2 outros. Quanto aos achados clínicos, resumidos na Tabela 3 , observamos em 13 seminaristas aumento de gânglios cervicais, axilares e inguinais, atingindo as dimensões de 1 a $1,5 \mathrm{~cm}$. Em 3 outros alunos não havia infartamento ganglionar, mas o fígado e o baço eram palpáveis. Em 2 casos, o exame físico foi inteiramente negativo e nos 10 restantes havia apenas micropoliadenopatia generalizada. E interessante verificar que o $\mathbf{n}^{\circ}$ $34 \mathrm{~A}$ nada apresentava ao exame físico na 1. ${ }^{\text {a }}$ vez e 3 meses depois, além de adenopatia cervical e axilar, o fígado e o baço estavam aumentados. No entanto, não teve qualquer sintomatologia e os títulos das reações específicas tiveram pronunciada queda. Quanto ao n. ${ }^{\circ} 35 \mathrm{~A}$, em que o resultado de 1:4000 se manteve, não houve alterações do primeiro ao segundo exame. Êste aluno queixou-se de tonturas e desmaios em meados de novembro de 1965. 0 caso n. $36 \mathrm{~A}$, cujos títulos também sofreram sensivel diminuição, apresentou um gânglio axilar esquerdo bem aumentado e uma hepatomegalia moderada. Relativamente à queixas, o aluno $n .^{\circ} 9 \mathrm{~A}$ teve cefaléia e febre em outubro de 1965; o n. ${ }^{\circ} 16 \mathrm{~A}$, em meados de novembro teve febre alta, o n. ${ }^{\circ}$ 18A referiu astenia; o n. ${ }^{\circ}$ 19A teve quadro febril e cefaléia em fins de outubro; o n. $20 \mathrm{~A}$ vinha apresentando picos febrís há 2 meses (mais tarde constatou-se malária) e os demais 23 alunos rão relataram sintomas sugestivos de processo infeccioso. Não foi possivel obter dados mais pormenorizados. Dentre os padres examinados nada se apurou do ponto de vista clínico. Em 3 
MAGaldI, C. et alii - Surto de toxoplasmose em um seminário de Bragança Paulista, SP. Aspectos clínicos, sorológicos. Rev. Saúde públ., S. Paulo, 1(2):141-171, dez. 1967.

\section{T A B ELA 2}

Surto de toxoplasmose em um Seminário de Bragança Paulista (SP). Seguimento sorológico em 9 seminaristas internados na Clínica de Doenças Tropicais e Infectuosas do Hospital das Clínicas da FMUSP.

\begin{tabular}{|c|c|c|c|c|c|c|c|c|}
\hline \multicolumn{2}{|c|}{ Dias de Doencas } & \multirow[t]{2}{*}{33} & \multirow[t]{2}{*}{40} & \multirow[t]{2}{*}{48} & \multirow[t]{2}{*}{57} & \multirow[t]{2}{*}{100} & \multirow[t]{2}{*}{114} & \multirow[t]{2}{*}{140} \\
\hline Casos & Reaçôes & & & & & & & \\
\hline \multirow{2}{*}{ N.O 1 (1) } & SF & $1: 16000$ & $1: 8000$ & $1: 8000$ & $1: 4000$ & $1: 8000$ & $1: 16000$ & $1: 16000$ \\
\hline & IF & $1: 32000$ & $1: 8000$ & $1: 8000$ & $1: 8000$ & $1: 8000$ & $1: 16000$ & $1: 32000$ \\
\hline \multirow{2}{*}{ N.o 2} & SF & $1: 1024$ & $1: 64$ & $1: 64$ & $1: 64$ & $1: 64$ & $1: 1024$ & $1: 4000$ \\
\hline & $\mathbf{I F}$ & $1: 1024$ & 1:64 & $1: 64$ & $1: 64$ & $1: 64$ & $1: 1024$ & $1: 1024$ \\
\hline \multirow{2}{*}{ N.O $3(1)$} & SF & $1: 4000$ & $1: 1024$ & $1: 1024$ & $1: 1024$ & $1: 4000$ & $1: 16000$ & 1:16000 \\
\hline & IF & $1: 4000$ & 1:1024 & 1:1024 & 1:1024 & $1: 4000$ & $1: 16000$ & $1: 16000$ \\
\hline \multirow{2}{*}{ N.0 4} & $\mathbf{S F}$ & $1: 4000$ & $1: 4000$ & $1: 4000$ & $1: 4000$ & $1: 16000$ & $1: 8000$ & \multirow{2}{*}{$\begin{array}{c}\text { não rea- } \\
\text { lizados }\end{array}$} \\
\hline & IF & $1: 1024$ & $1: 4000$ & $1: 4000$ & $1: 4000$ & $1: 16000$ & 1:8000 & \\
\hline \multirow{2}{*}{.N. 5} & SF & $1: 256$ & $1: 8000$ & 1:4000 & $1: 4000$ & $1: 8000$ & $1: 8000$ & $1: 8000$ \\
\hline & IF & $1: 256$ & $1: 8000$ & $1: 4000$ & $1: 4000$ & $1: 8000$ & $1: 8000$ & $1: 8000$ \\
\hline \multirow{2}{*}{ N.0 6 (1) } & SF & $1: 32000$ & $1: 8000$ & $1: 16000$ & $1: 160 n 0$ & $1: 16000$ & 1:8000 & $1: 8000$ \\
\hline & IF & $1: 32000$ & $1: 8000$ & $1: 16000$ & $1: 16000$ & 1:16000 & 1:8000 & $1: 8000$ \\
\hline \multirow{2}{*}{ N.O 7} & SF & $1: 16000$ & $1: 8000$ & $1: 4000$ & $1: 4000$ & $1: 4000$ & $1: 4000$ & $1: 8000$ \\
\hline & IF & $1: 16000$ & 1:8000 & $1: 4000$ & 1:4000 & 1:4000 & $1: 4000$ & $1: 8000$ \\
\hline \multirow[t]{2}{*}{ N.0 8} & SF & $1: 8000$ & $1: 8000$ & $1: 8000$ & $1: 4000$ & 1:1024 & $1: 1024$ & \multirow{2}{*}{$\begin{array}{c}\text { não rea- } \\
\text { lizados }\end{array}$} \\
\hline & IF & $1: 8000$ & $1: 8000$ & $1: 4000$ & $1: 4000$ & $1: 1024$ & $1: 1024$ & \\
\hline \multirow{2}{*}{ N.0 9} & SF & $1: 1024$ & 1:8000 & 1:8000 & $1: 8000$ & $1: 8000$ & $1: 4000$ & 1:4000 \\
\hline & $\mathbf{I F}$ & $1: 1024$ & $1: 4000$ & $1: 4000$ & $1: 4000$ & $1: 8000$ & $1: 4000$ & $1: 8000$ \\
\hline
\end{tabular}

(1) - Inoculação de gânglio em camundongos adultos, examinados após 10 dias. Resultado positivo para Toxoplasma gondii

SF - Reação de Sabin-Feldman

IF - Reação de imunofluorescência indireta

seminaristas com reação positiva a $1: 4000$ em que foi tentado o isolamento do toxoplasma nas fezes, o resultado foi negativo. Nas visitas realizadas posteriormente ao Seminário, (a última foi em 11-8-1966, quase 10 meses após o surto), fomos informados de que não apareceram casos novos de toxoplasmose.
Colonos da fazenda - Os resultados das reaçōes de Sabin-Feldman e imunofluorescência e os achados de exame físico estão consignados na Tabela 4 , onde agrupamos os indivíduos numerados de lB a 36B, segundo os respectivos agregados familiares. Os números $1 \mathrm{~B}$ e $4 \mathrm{~B}$ são empregados do Seminário, o número 
MAGALDI, C. et alii - Surto de toxoplasmose em um seminário de Braganca Paulista, SP. Aspectos clínicos, sorológicos. Rev. Saúde pübl., S. Paulo, 1(2):141-171, dez. 1967.

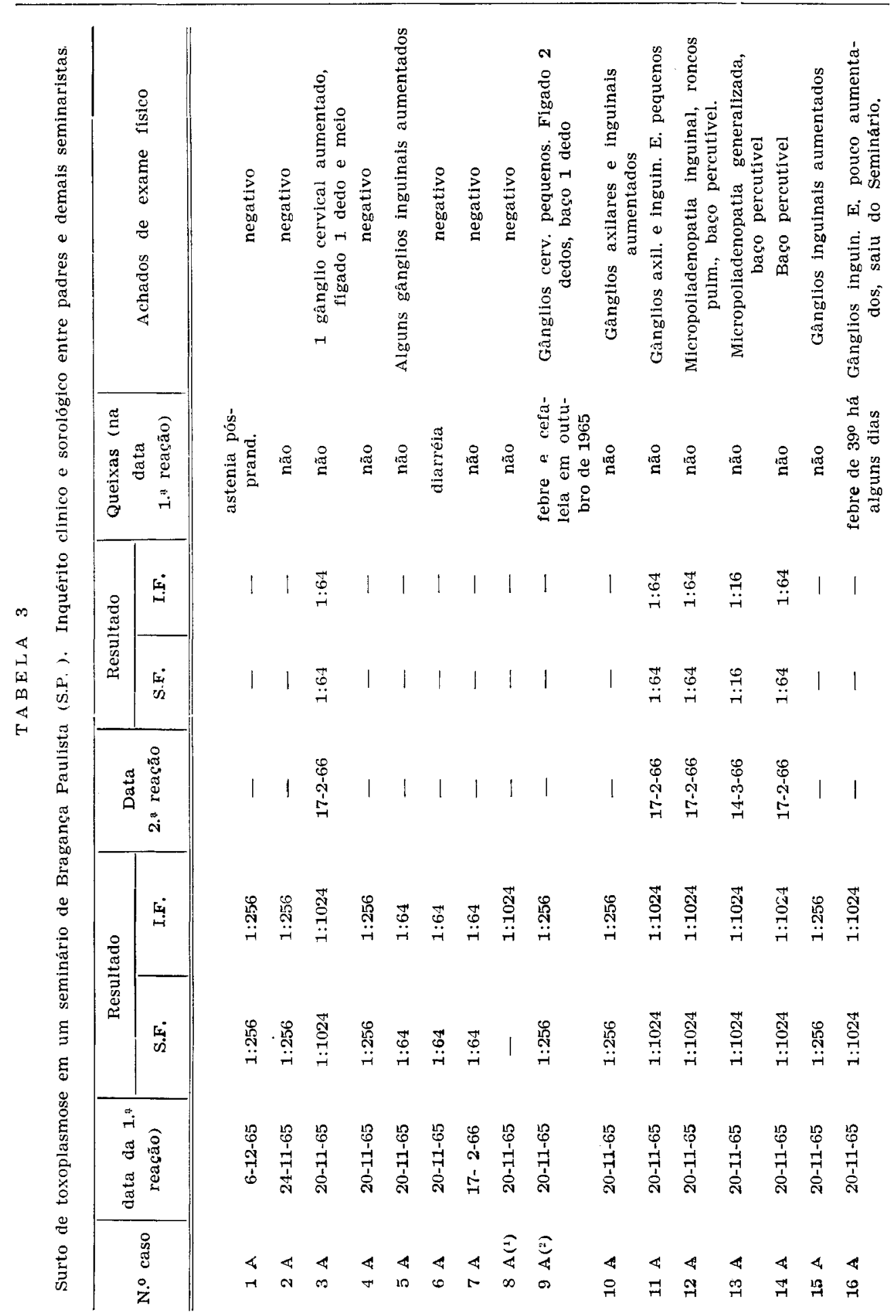


MAGALDI, C. et alii - Surto de toxoplasmose em um seminário de Bragança Paulista, SP. Aspectos clínicos, sorológicos. Rev. Saúde puibl., S. Paulo, 1(2):141-171, dez. 1967.

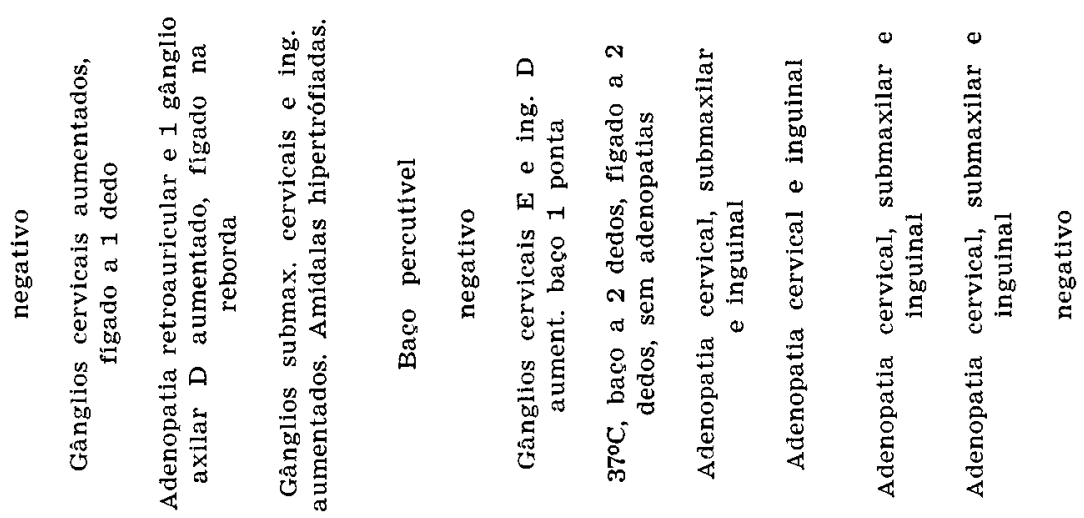

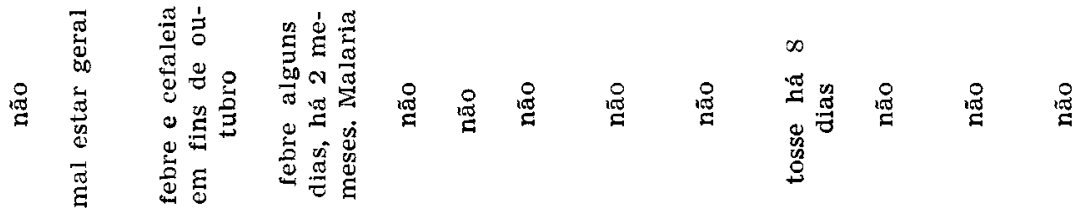

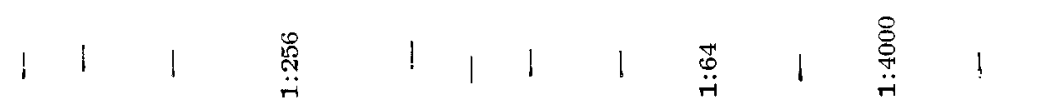

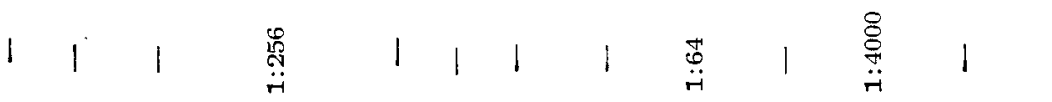

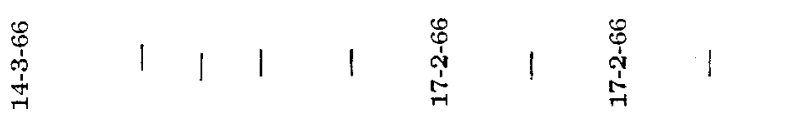

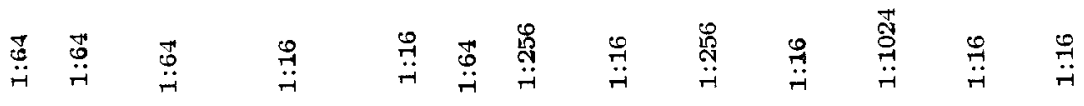

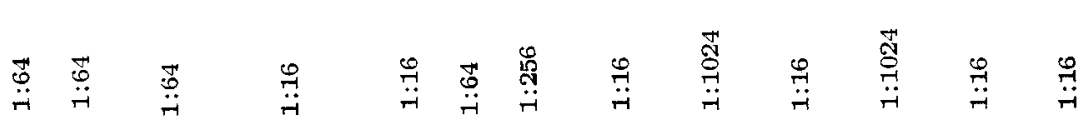

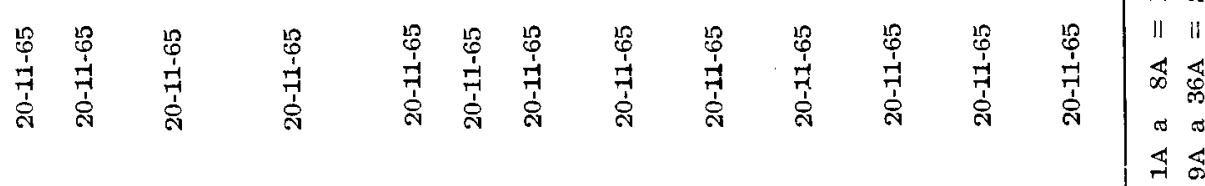

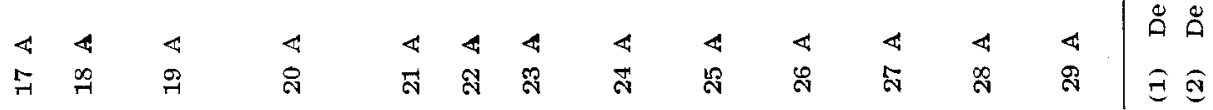


MAGALDI, C. et aliii - Surto de toxoplasmose em um seminário de Bragança Paulista, SP. Aspectos clínicos, sorológicos.. Rev. Saúde públ., S. Paulo, 1(2):141-171, dez. 1967.

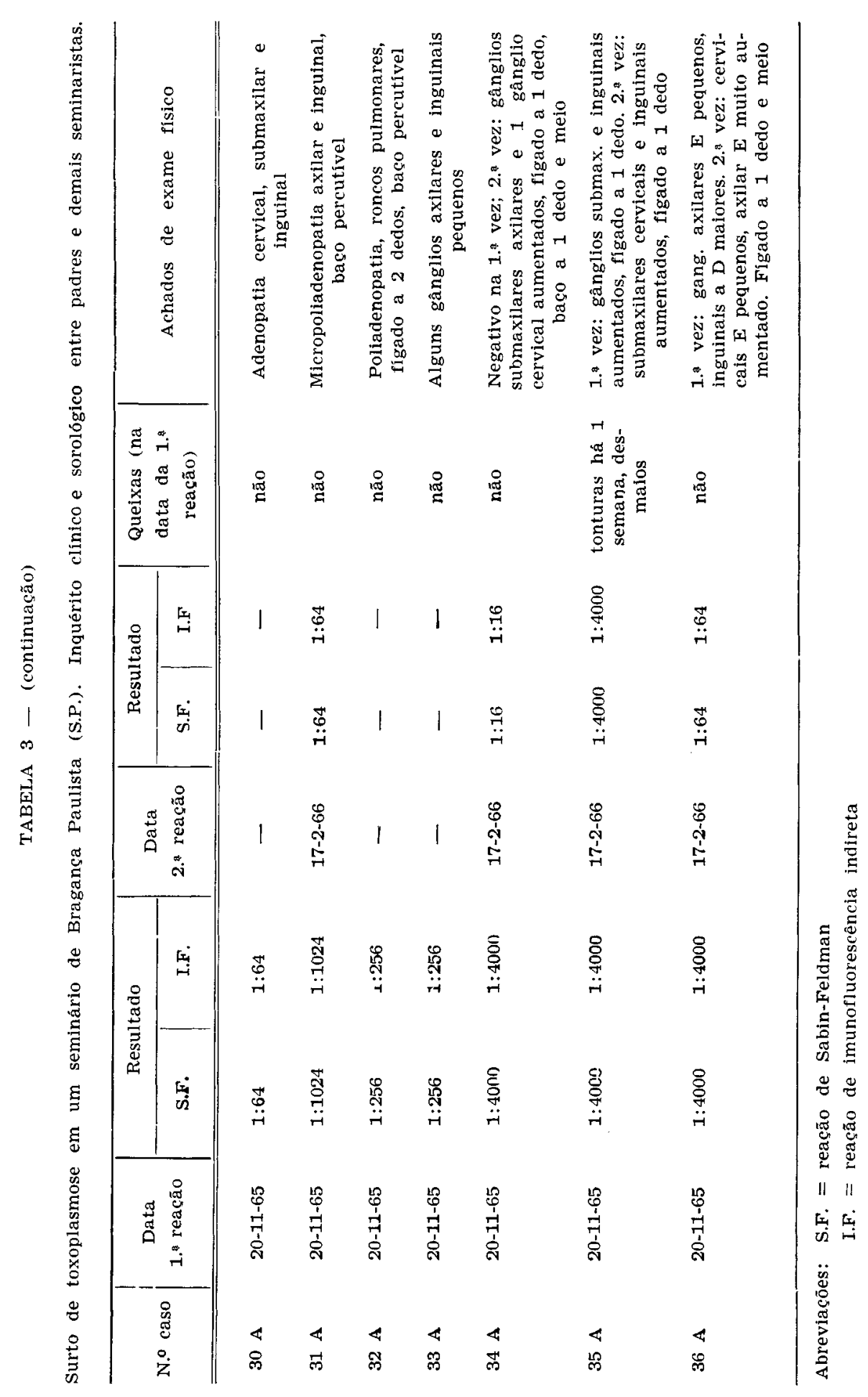


MAGALDI, C. et alii - Surto de toxoplasmose em um seminário de Bragança Paulista, SP. Aspectos clínicos, sorológicos. Rev. Saúde públ., S. Paulo, 1(2):141-171, dez. 1967.

1B também trabalhava na lavoura e residia na Colônia.

Em 8 casos, os resultados para uma ou ambas reaçōes foram positivas a $1: 1024$. Em 9, encontramos títulos $\geq 1: 4000$. Dentre os inicialmente positivos a $1: 1024$, apenas no caso $22 \mathrm{~B}$ o título se manteve, havendo queda de título em 4 casos que foram examinados pela segunda vez. Em 9 indivíduos com títulos $\geq 1: 4000$, observamos os seguintes fatos: em 2 casos (n. ${ }^{\circ} \mathrm{IB}$ e 18B) o título não se manteve, em 2 casos (4B e 32B) não foi possível a repetição das provas e em 4 casos (17B, $26 \mathrm{~B}, 27 \mathrm{~B}$ e $35 \mathrm{~B}$ ) o título continuou elevado. Resta ainda informar que o número $34 \mathrm{~B}$, cujas reações em 20-11-65 foram positivas a 1:256, em 28-1-66 e 25-2-66 foram positivas em título de 1:4000. Nesse caso, as reações foram refeitas em virtude de ter sido referida febre em fins de dezembro de 1965 e início de janeiro de 1966. Conforme será adiante mencionado, êste caso foi internado para estudo, assim como os n. ${ }^{\circ} \mathrm{s} 17 \mathrm{~B}$ e $35 \mathrm{~B}$.

Ao lado do encontro bastante comum de gânglios palpáveis não aumentados, em todos setores e hepatomegalia discreta em alguns casos, certos achados de exame são interessantes e merecem ser comentados, principalmente naqueles casos em que se pôde realizar um segundo exame clínico ou em que as reaçoes foram positivas em título diagnóstico. Assim, no caso $4 \mathrm{~B}$ ao $2 .^{\circ}$ exame palpou-se fígado aumentado; no caso $8 \mathrm{~B}$ cujas provas foram feitas só em 17-2-66, notou-se infartamento gânglionar de vulto, mormente nas axilas; no caso 25B, além de hipertermia e amidalite, palpou-se um gânglio axilar bastante aumentado e o fígado a 2 dedos da reborda $\mathrm{e}$ no caso $26 \mathrm{~B}$, o baço apresentou-se palpável no $2 .^{\circ}$ exame. Os casos $26 \mathrm{~B}$ e $27 \mathrm{~B}$ são 2 irmãos de 5 a 4 anos que, embora sem queixas, apresentavam micropoliadenopatia difusa e hepatomegalia, além de reações que continuaram positivas a $1: 4000$, até 3 meses depois do $1 .^{\circ}$ exame. Por outro lado, em um adulto (n. $\left.{ }^{\circ} 31 \mathrm{~B}\right)$, com reações positivas a $1: 4000$ e queixas su- gestivas de toxoplasmose, o exame físico foi completamente negativo. É curioso observar que a única família com crianças em que nada se apurou ao exame físico e em que não houve nenhum caso positivo, é a constituída pelos números $19 \mathrm{~B}$ e $24 \mathrm{~B}$ e que vive em condiçōes sócio-econômicas algo melhores do que as demais familias.

Em 8 colonos (4 com reações em título $1: 4000$ e 4 com títulos inferiores) a inoculação de fezes em camundongo não ensejou o isolamento de toxoplasmas.

Cumpre comentar os casos 17B, 34B e $35 \mathrm{~B}$ que foram internados na Clínica de Doenças Tropicais e Infectuosas do Hospital das Clínicas da F.M.U.S.P. 0 número 17B é um menino de 7 anos (E.C.) que ao primeiro exame, em 24-11-65, apresentava micropoliadenopatia cervical, submaxilar e axilar e fígado a 2 dedos da reborda. Nessa ocasião, as reações foram positivas a 1:16000. Reexaminado em 17-2-1966, estava com $37^{\circ} \mathrm{C}$, taquicardia, adenopatia difusa, com gânglios bem maiores e fígado nas mesmas dimensões. Tendo sido referida uma história de febre esporádica, cefaléia, dor abdominal, anorexia e emagrecimento, foi internado para observação. A segunda reação de SabinFeldman em 18-2-1966 foi positiva a $1: 8000$. A inoculação de gânglio em camundongo permitiu o isolamento de toxoplasmas. A inoculação de fezes foi negativa. Foi assinalada hiperplasia reticular ao exame histológico do gânglio. Esste caso apresentou um quadro clínico, radiológico e eletrocardiográfico de miocardite, pelo que permaneceu internado até agôsto de 1966. O pai do paciente teve reações iniciais positivas a $1: 1024$ e em uma irmã de 3 anos, com discreta hepatomegalia e sem história sugestiva, os primeiros resultados foram positivos a $1: 4000$. 0 doente em questão vivia em condições sócio-econômicas precárias, comia carne de vaca e ovos muito raramente e não bebia leite. Tinha contato com cães, gato e galinhas. O cão "Helio" de sua casa teve reação a $1: 256$, nunca exibindo sinais de 
MAGALDI, C. et alii - Surto de toxoplasmose em um seminário de Bragança Paulista, SP. Aspectos clínicos, sorológicos. Rev. Saúde públ., S. Paulo, 1(2):141-171, dez. 1967.

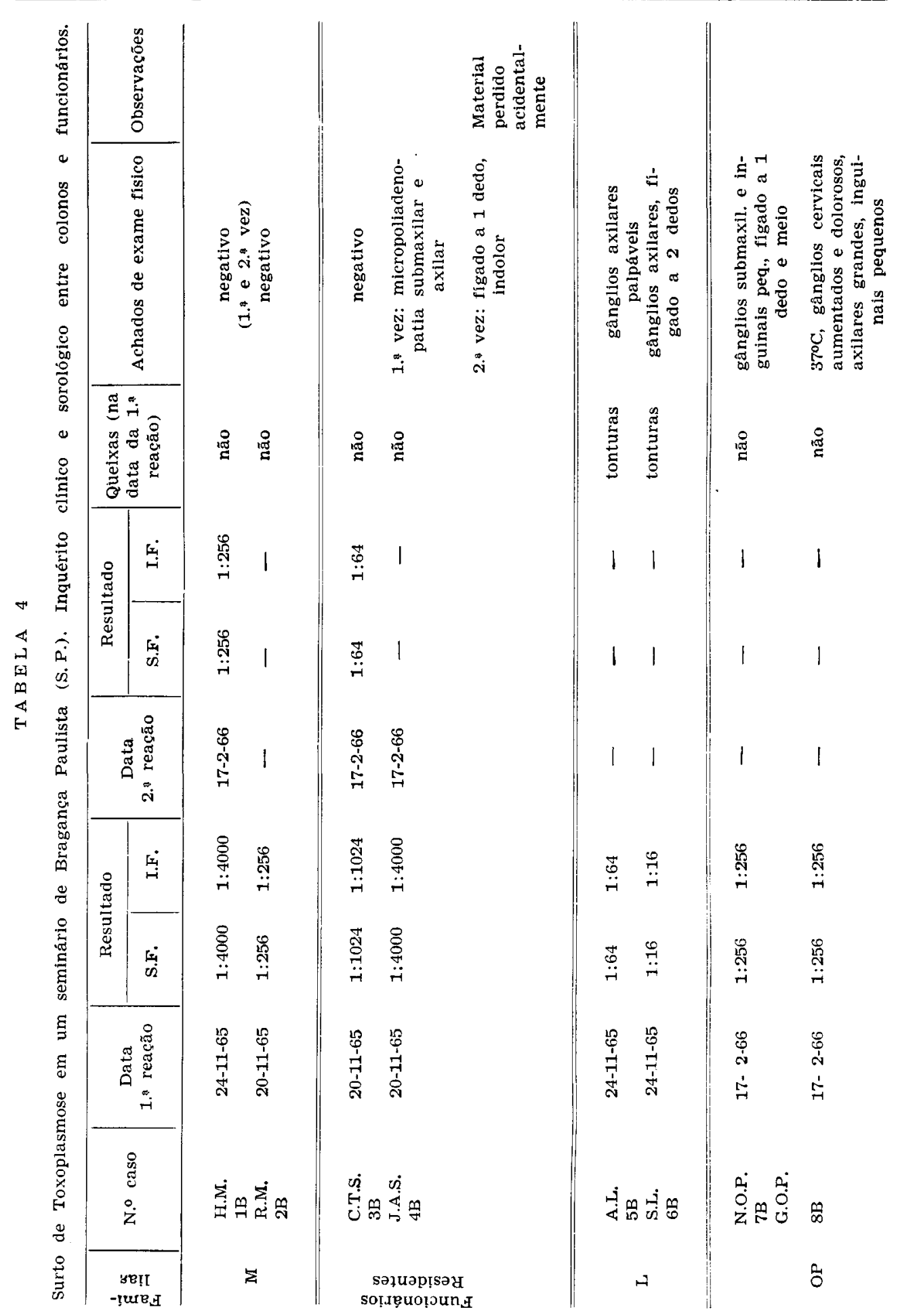


MAGALDI, C. et alii - Surto de toxoplasmose em um seminário de Braganç Paulista, SP. Aspectos clínicos, sorológicos. Rev. Saúde públ., S. Paulo, 1(2):141-171, dez. 1967.

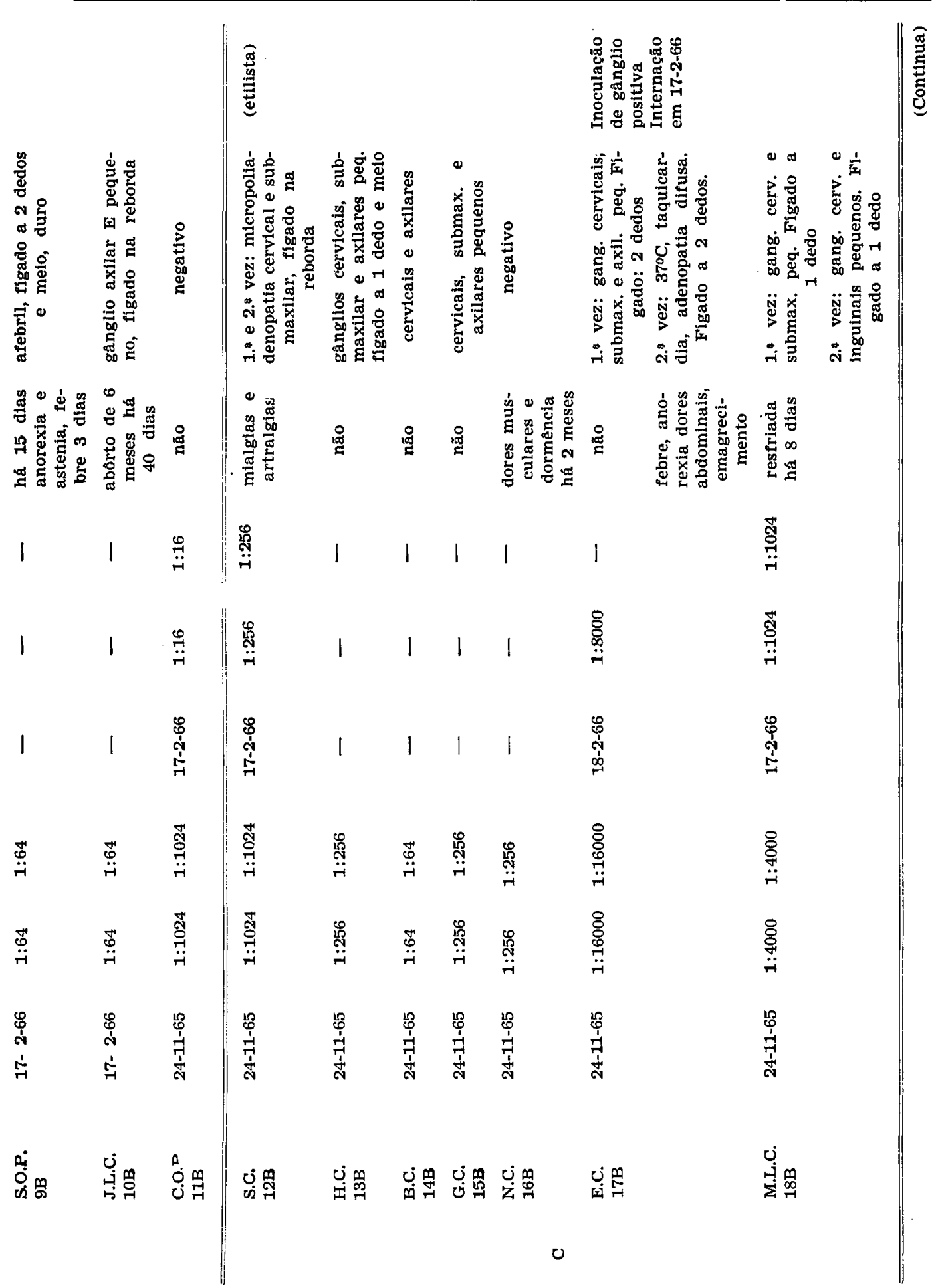


MAGALDI, C. et alii - Surto de toxoplasmose em um seminário de Bragança Paulista, SP. Aspectos clínicos, sorológicos. Rev. Saúde puibl., S. Paulo, 1(2):141-171, dez. 1967.

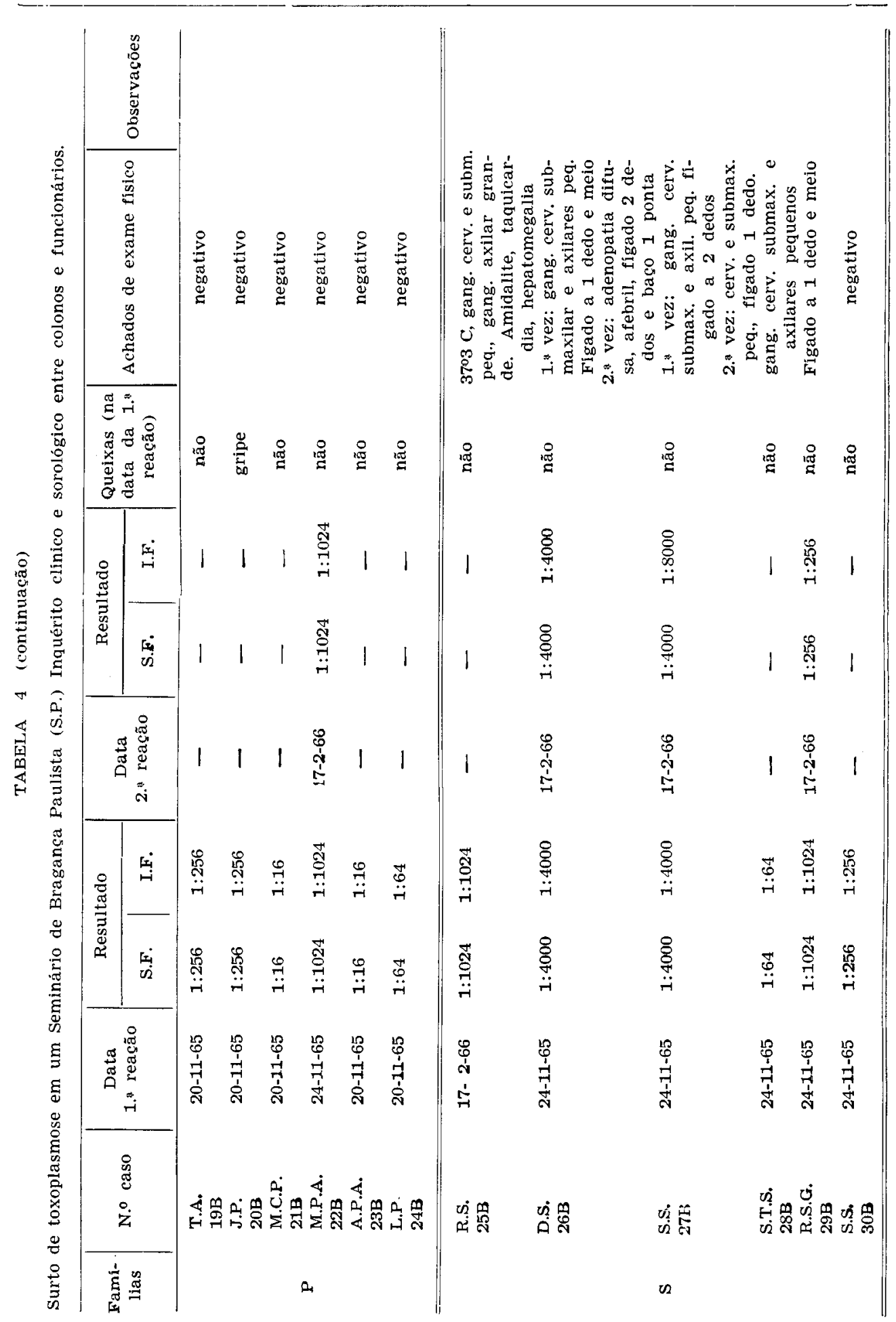


MAGALDI, C. et alii - Surto de toxoplasmose em um seminário de Bragança Paulista, SP. Aspectos clinicos, sorológicos.
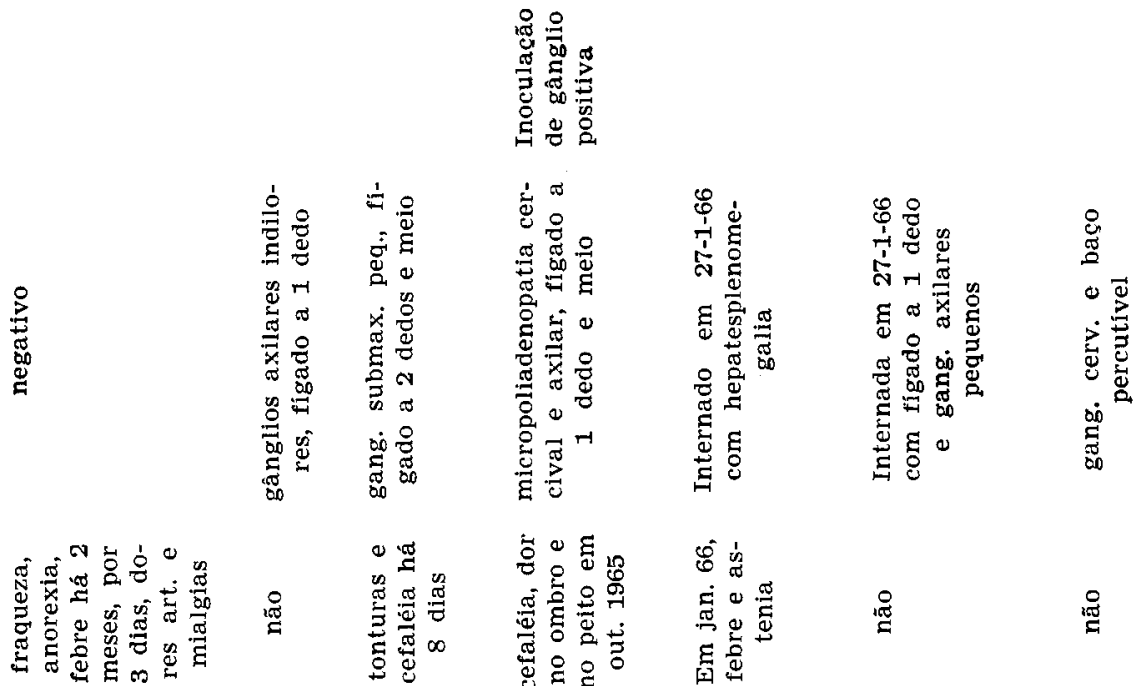

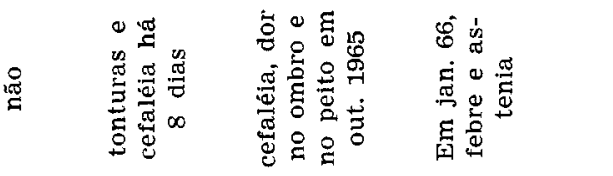

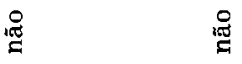

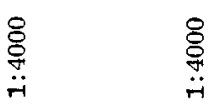

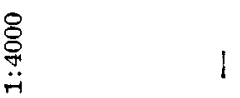

1

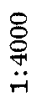

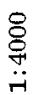

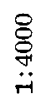

1

I

$1 \quad 1 \quad \begin{aligned} & 0 \\ & 1 \\ & 1 \\ & 0 \\ & 0 \\ & 0\end{aligned}$

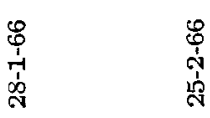

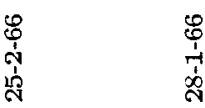

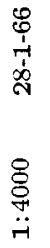

1

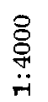

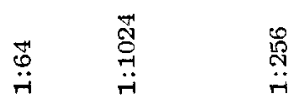

꼰

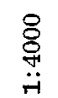

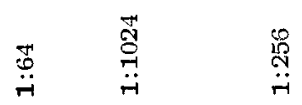

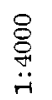

$\stackrel{\text { i⿱口 }}{\stackrel{4}{4}}$

ڤ̊ำ

담

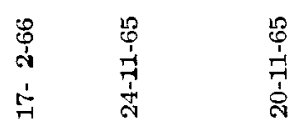

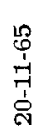

㝵

1

$\stackrel{\square}{\square}$

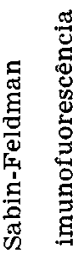

$\approx$

:

II II

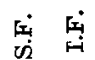

सं की

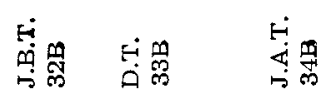

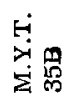

芦番

E

范 
MAGALDI, C. et alii - Surto de toxoplasmose em um seminário de Bragança Paulista, SP. Aspectos clínicos, sorológicos. Rev. Saúde públ., S. Paulo, 1(2):141-171, dez. 1967.

doença. 0 caso $34 \mathrm{~B}$ (J.A.T.) de 13 anos foi considerado como suspeito de toxoplasmose em 20-11-65, quando foi colhido sangue pela 1 . $^{a}$ vez, em virtude de contato diário com carneiros doentes e cães. Ao exame, notava-se micropoliadenopatia cervical e axilar e fígado palpado a 1 dedo e meio. Referia apenas cefaléia esporádica e dor no ombro esquerdo. As reações iniciais foram positivas a $1: 256$. Em 27-1-66 foi internado por apresentar astenia e febre moderada. Nessa data, o teste do corante foi positivo a 1:4000 e um mês após êsse título se manteve. Foi retirado um gânglio e a sua inoculação em camundongo, resultou positiva para toxoplasmas. O exame histopatológico revelou hiperplasia linfática e reticular do gânglio. Além de contato com ovinos tinha hábito de tomar água de bicas onde vacas e carneiros também matam a sêde. O cão "Duque", de sua propriedade, quic. vivia junto ao rebanho teve reação de Sabin-Feldman positiva a $1: 4000$. Em fevereiro de 1966, êste mesmo cão foi mor. to por parecer raivoso. Entre os famlia. res do paciente houve mais 2 casos posi tivos a $1: 4000$, um dos quais com exare físico negativo e outro que foi internedo. $O$ caso $35 \mathrm{~B}$, uma môça de 18 anos, irmã do caso anterior, internada também para observação em 27-1-1966, não referiu qualquer sintomatologia e ao exame clíniconico apresentava alguns gânglios axilares pouco aumentados e fígado a 1 dedo. Neste caso não foi efetuada a biópsia de inoculação de gânglio. As reações sorológicas mantiveram-se em título de $1: 4000$ em 28-1-66. Em 30-11-65 a paciente havia se casado e estava residindo longe do Seminário.

$\mathrm{Na}$ Tabela 5 , referente ao inquérito sorológico abrangendo padres, alunos, funcionários, colonos e familiares, os títulos das reações de Sabin-Feldman e imunofluorescência estão distribuídos em grupos de 1 a 7 , afim de proporcionar uma fácil e rápida apreciação dêsses dados, em conjunto.

Animais - Em 6-12-65, com a valiosa colaboração do Dr. A. F. Pestana de CASTro ${ }^{(1)}$, foram retiradas amostras de sangue de 20 carneiros e ovelhas, 5 porcos e 5 cães, para o teste do corante. Para os ovinos, numerados de I a XX, obtiveram-se os seguintes resultados:

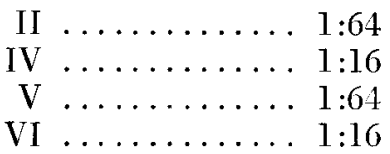

T A B E L A 5

Surto de toxoplasmose em um Seminárío de Bragança Paulista (SP). Inquérito sorológico entre 72 pessoas. Distribuição dos títulos das reações de Sabin-Feldman e imunofluorescência

\begin{tabular}{clcc}
\hline Grupos & Títulos & $\begin{array}{c}\text { Seminaristas e } \\
\text { Padres }\end{array}$ & $\begin{array}{c}\text { Funcionários, Colo- } \\
\text { nos e Familiares }\end{array}$ \\
\hline II & Positivos até $1: 6$ & 6 & $\mathbf{3}$ \\
III & Positivos até $1: 64$ & 8 & 7 \\
IV & Positivos até $1: 256$ & 9 & $10\left(^{(2)}\right.$ \\
V & Positivos até $1: 1024$ & $10(1)$ & 8 \\
VI & Positivos até $1: 4000$ & 3 & 7 \\
VII & Positivos até $1: 8000$ & 0 & 0 \\
\hline Total de casos & Positivos até $1: 16000$ & 0 & $1\left(^{(3)}\right.$ \\
\hline
\end{tabular}

(1) 1 caso com título 1:4000 após 90 dias.

(2) 1 caso $\mathrm{ccm}$ título 1:4000 e inoculação de gânglio positiva para toxoplasmose após 60 días.

(3) Caso de inoculação de gânglio positiva.

(1) Médico Veterinário do Instituto Biológico - São Paulo. 
MAGALDI, C. et alii - Surto de toxoplasmose em um seminário de Bragança Paulista, SP. Aspectos clínicos, sorológicos. Rev. Saúde públ., S. Paulo, 1(2):141-171, dez.-1967.

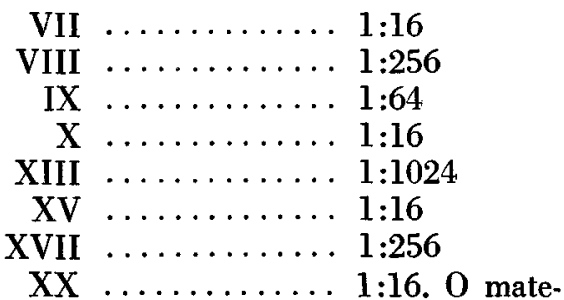

rial colhido dos carneiros I, III, XI, XII, XIV, XVI, XVIII e XIX foi perdido acidentalmente.

Para os cães sangrados em 6-12-65, os resultados são os seguintes:

"Duque" (pertence ao caso 34B) 1:4000 "Hélio" (pertence ao caso 13B) 1:256

"Marfim" (pertence ao caso 29B) 1:1024

"Chucho" (pertence ao caso 7A) 1:1024

"Cuca" (pertence ao caso 7A) 1:1024

Em relação aos porcos, numerados de 1 a $5 \mathrm{P}$, temos os seguintes resultados:

N. ${ }^{\circ}$ 1P $\ldots \ldots \ldots 1: 16$

N. ${ }^{\circ} 2 \mathrm{P} \ldots \ldots \ldots 1: 16$

N. ${ }^{\circ} 3 \mathrm{P} \ldots \ldots \ldots, 1: 64$

N. ${ }^{\circ} 4 \mathrm{P} \ldots \ldots \ldots 1: 64$

acidentalmente.

$\mathrm{N} .{ }^{\circ} 5 \mathrm{P} \ldots \ldots$ material perdido

Em 14.3-66 foram sangrados 5 cães, com repetição das provas nos cảes "Marfim" e "Chucho". Resultados das reações:

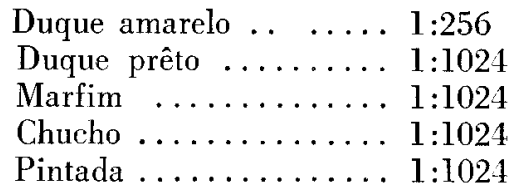

Os cães "Duque amarelo", "Duque prêto" e "Pintada" são de propriedade da família O.P. Foi enviado ao Instituto Biológico de São Paulo, aos cuidados do Dr. Waldir George, em 10-2-66, um carneiro doente. 0 exame histopatológico e a inoculação de orgãos do animal foram negativos para toxoplasmose. Foi verificada apenas uma míase. Posteriormente, foi autopsiado, outro carneiro recém-morto em início de decomposição, para exame helmintológico o qual se revelou posi- tivo (infestação maciça) para Haemonchus contortus. Dos mesmos 5 cães sangrados em 14-3-66 foi colhido material fecal para inoculação e pesquisa de toxoplasma em camundongo, com resultado negativo. Foi capturado um exemplar de $R$. rattus rattus, em armadilha colocada junto ao abrigo dos carneiros. As fezes foram inoculadas, assim como o macerado dos vísceras e cérebro obtidos do animal, não tendo sido isolado o parasita, após observação de 30 dias. Em virtude dos milharais e da abundância de alimentos esparsos na zona, foi impossivel a captura de maior número de ratos.

Inquérito sorológico entre seminaristas admitidos em 1966 - Com a finalidade de verificar a situação imunológica de estudantes admitidos no início do ano letivo de 1966, frente à toxoplasmose e surpreender possíveis alteraçốes de anticorpos específicos, após alguns meses de permanência no Seminário, fichamos, examinamos e colhemos sangue de. 21 alunos novos. A idade média do grupo, foi de 12,9 anos, todos de côr branca. A procedência dêles coincide quase com a dos alunos mais antigos: São Paulo, Capital e interior do Estado, adjacências de Bragança, Goiás, Minas Gerais e Mato Grosso, em geral de zona rural e com contato anterior com gado bovino e outras espécies animais. A data do ingresso variou de 25-1-66 até 6-3-66.

A primeira colheita foi em 14-3-66 e a segunda em 11-8-66, por conseguinte quase 5 meses depois. Nas férias de julho os alunos regressaram às suas casas. $\mathrm{Na}$ Tabela 6, estão expressos os resultados das provas sorológicas e dos dados de exame físico. Apenas 2 seminaristas tiveram reaçôes iniciais positivas a 1:1024 e em 4 os títulos foram de 1:4000. Dêstes, apenas 2 casos (P.P. e J.C.G.) tinham infartamento ganglionar nítido; nos 2 restantes, verificou-se adenopatia submaxilar e discreta hepatomegalia (caso L.A.G.) e exame físico sem sinais de comprometimento ganglionar ou visceral (caso J.R.L.). O aluno T.F.B. desenvolveu quadro febril, 
MAGALDI, C. et alii - Surto de toxoplasmose em um seminário de Bragança Paulista, SP. Aspectos clínicos, sorológicos. Rev. Saúde públ., S. Paulo, 1(2):141-171, dez. 1967.

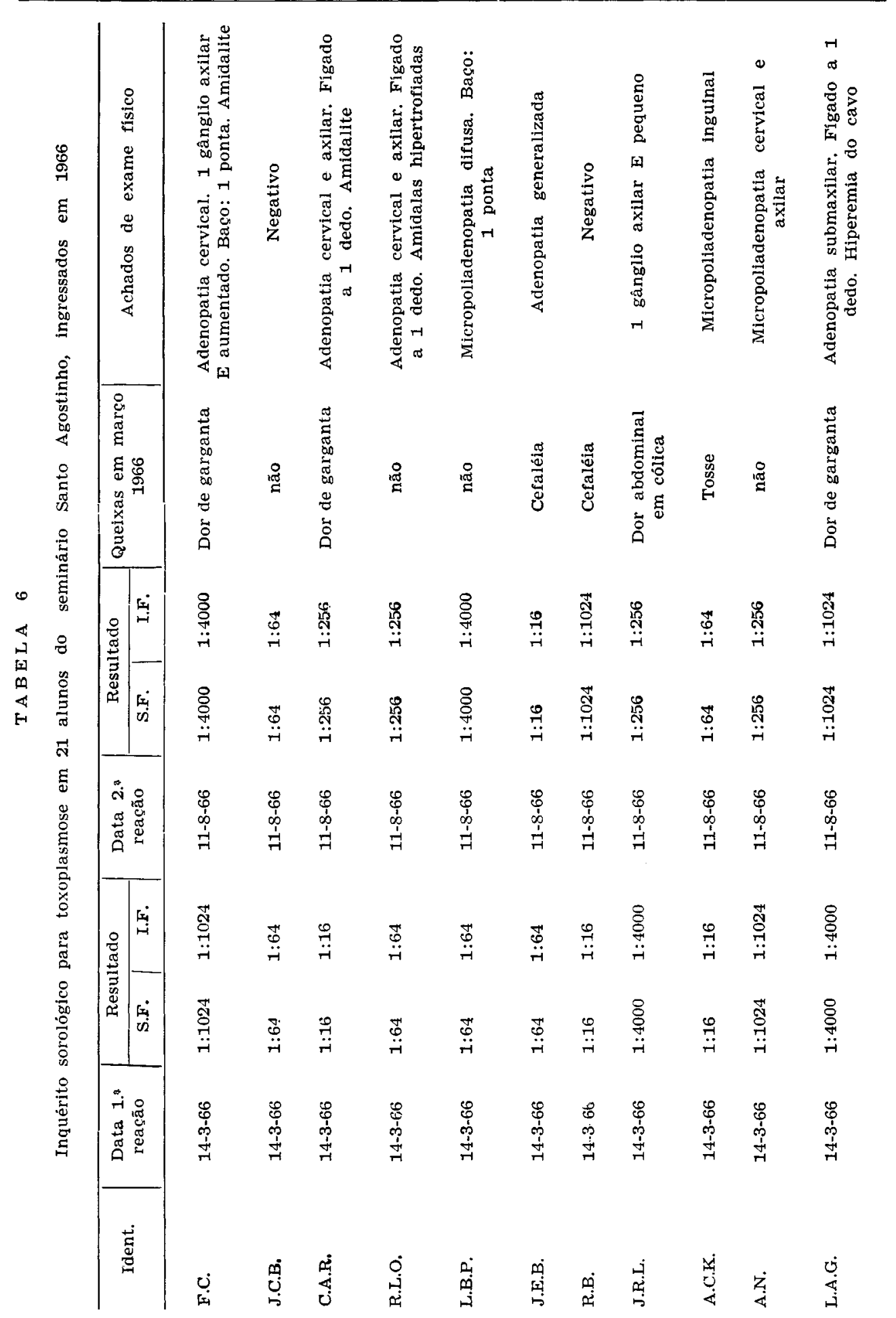


MAGALDI, C. et alil - Surto de toxoplasmose em um seminário de Braganca Paulista, SP. Aspectos clínicos, sorológicos. Rev. Saúde públ., S. Paulo, 1(2):141-171, dez, 1967.

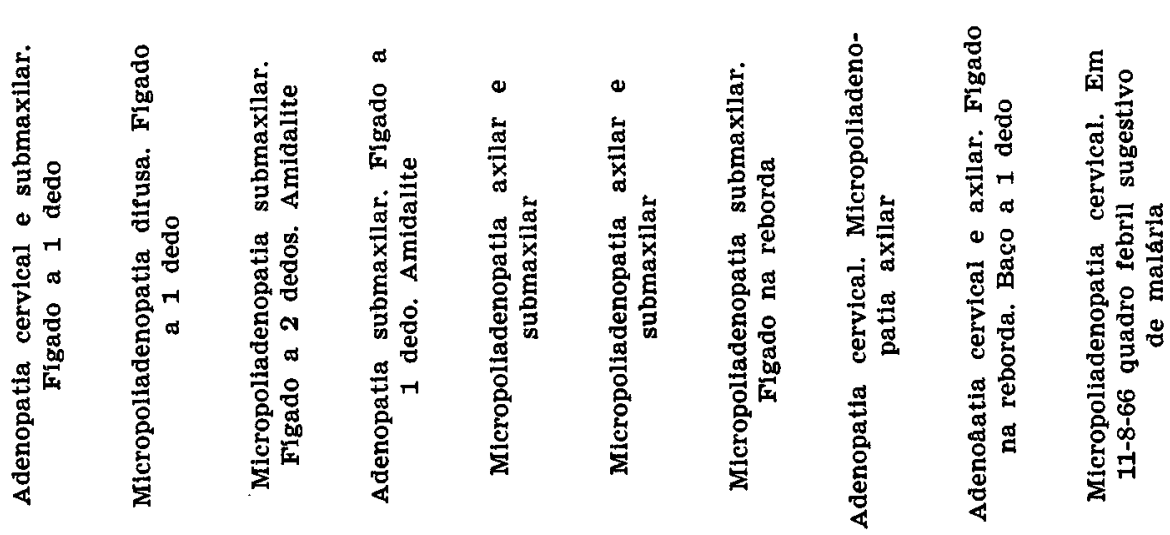

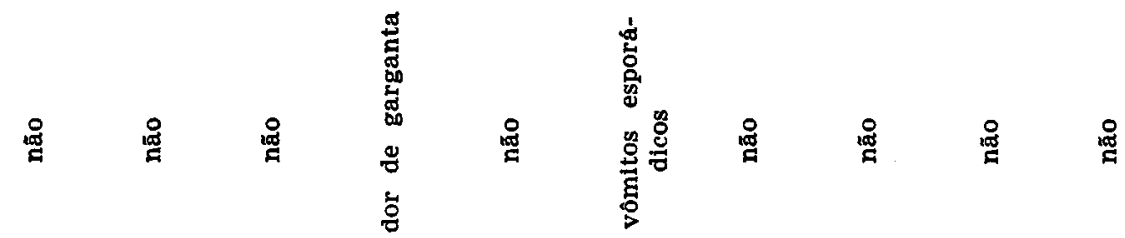

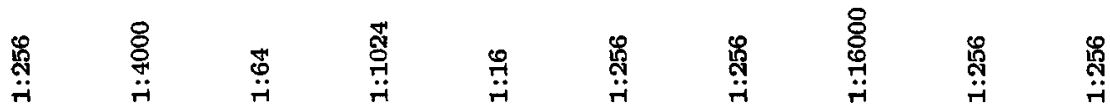

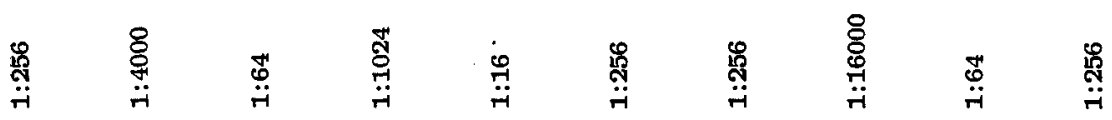

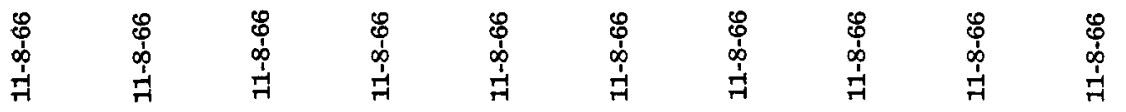

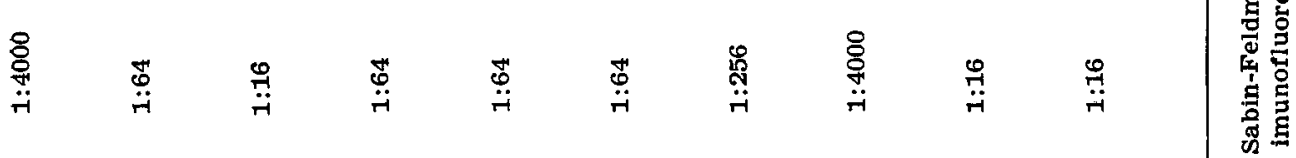

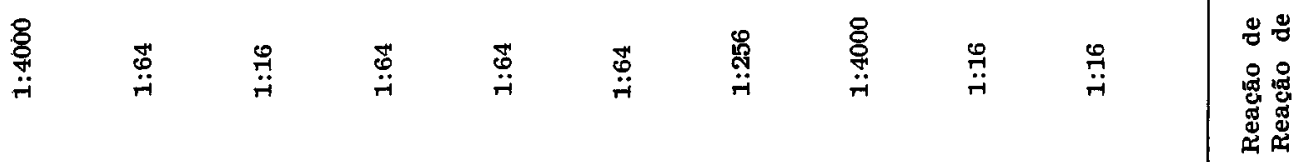

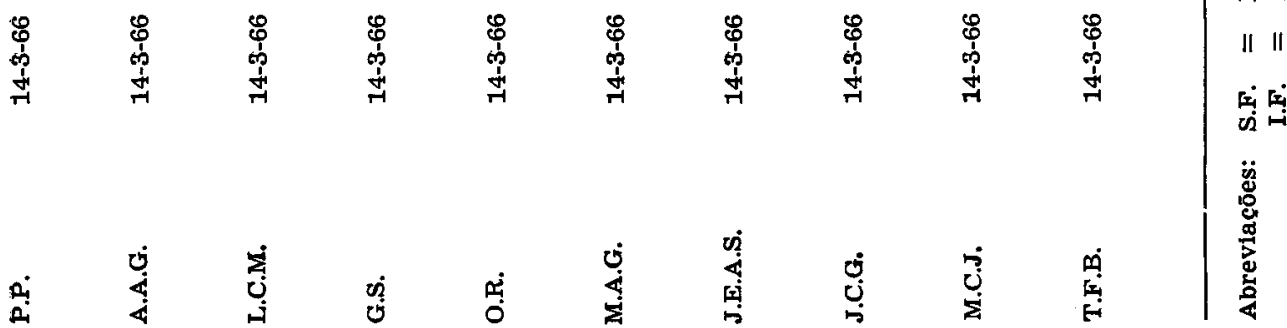


MAGALDI, C. et alii - Surto de toxoplasmose em um seminário de Bragança Paulista, SP. Aspectos clínicos, sorológicos. Rev. Saúde públ., S. Paulo, 1(2):141-171, dez. 1967.

em agôsto de 1966, após ter voltado de Goiás onde passara as férias. Apresentou, nessa ocasião, anemia e esplenomegalia. A reação de Widal e a prova de aglutinação rápida para brucelose foram negativas. Não foi pesquisada a presença de hematozoários em tempo útil, pois a febre cedeu e o facultativo que observou o paciente aguardou momento oportuno para a realização dêsse exame. Em relação aos resultados obtidos 5 meses depois, pode-se perceber que em 12 alunos houve aumento de título em ambas as provas, sendo que, em 5 êsse aumento foi bem evidente, incluíndo-se 3 casos em que a positividade atingiu a diluição de $1: 4000$. Êstes 3 últimos (F.C., L.B.P. e A.A.G.) não referiram qualquer sintomatologia no decurso de 5 meses, mas apresentavam desde a fase inicial de observação adenopatia e esplenomegalia moderadas, o $10^{\circ}$ e o $2 .^{\circ}$ e micropoliadenopatia e hepatomegalia, o $3{ }^{\circ}$ caso. Não foi possível, entretanto, a reavaliação clínica dêstes casos assim como daqueles 4 que já tinham provas positivas a 1:4000, ao primeiro exame sorológico. Quanto aos 4 que acabamos de mencionar, à repetição das provas, verificou-se queda de títulos em 3 e ascensão de título em 1 (caso J.C.G.).

\section{DISCUSS}

A forma linfoglandular da toxoplasmose descrita por SiIm ${ }^{25,26}(1951,1956)$ ficou bem caracterizada, sob o ponto de vista clínico e hematológico, em 11 casos internados. $O$ período de incubação da doença não pôde ser calculado porquanto - a fonte de infecção e a data do contágio permaneceram no terreno das hipóteses. A evolução foi favorável, sem sinais de localização em outros órgãos e sem recaídas. A mononucleose infecciosa, doença que ocorre com certa freqüência em instituições e comunidades ( REMINGTON et. alii $^{21,22}$, 1962, 1963) foi lembrada no diagnóstico diferencial, mas diante dos expressivos resultados sorológicos e do isolamento do $T$. gondii, não foi necessá- rio realizar a pesquisa de anticorpos heterófilos. Em uma criança de 7 anos, foi verificado um quadro de miocardite, com manifestações clínicas, eletrocardiográficas e radiológicas, tendo havido recuperação quase completa, por ocasião da alta.

0 diagnóstico definitivo foi possibilitado pelo isolamento do agente, ao lado dos resultados da sorologia; cumpre, porém, tecer alguns comentários acêrca dos títulos positivos registrados e do comportamento sorológico em 9 casos. Segundo demonstrou Camargo ${ }^{7}$ (1966), os resultados obtidos com as reaçôes de Sabin-Feldman e de imunofluorescência indireta são, em geral, superponíveis. Nesta casuística, encontramos, via de regra, resultados concordantes, havendo, quando muito, diferença de apenas 1 tubo de diluição. Confirmando o que tem sido observado em nosso meio, o título positivo mínimo considerado na prática como diagnóstico de toxoplasmose - doença é 1:4000 e êste foi o critério que adotamos neste inquérito, não deixando de valorizar, todavia, títulos algo inferiores a 1:4000 quando estavam relacionados a indivíduos com história sugestiva e quadro clínico compatível. No que diz respeito às flutuações de títulos observadas em alguns dos pacientes estudados por período prolongado, EICHENWALD ${ }^{12}$ (1956), já as havia observado, em adultos com infecção prévia mas não com doença ativa, não encontrando uma explicação definitiva para o fenômeno. Por outro lado, o aparecimento tardio de anticorpos detectáveis em diluições mais altas, registrado em pelo menos 3 indivíduos desta casuística, dependeria de um comportamento imunobiológico excepcional, pois via de regra, os anticorpos para a prov̄a do corante surgem de 2 a 3 semanas após a infecção e atingem títulos $\geq 1: 256$, persistindo elevados por meses e anos (S SABIN et alii ${ }^{24}$, 1952). 'Tais ocorrências ainda não bem elucidadas, devem ser lembradas na prática, quando se suspeita de toxoplasmose aguda e segundo TALHAMmer ${ }^{28}$ (1959), 
MAGALDI, C. et alil - Surto de toxoplasmose em um seminário de Bragança Paulista, SP. Aspectos clínicos, sorológicos.

Rev. Saúde públ., S. Paulo, 1(2):141-171, dez. 1967.

um caso agudo, na fase de diluições positivas baixas ou médias, excluindo-se a identificação do agente, só poderá ser diagnosticado através de curva de títulos obtidos a longo prazo, portanto com considerável perda de tempo. Nessas eventualidades, a intradermo-reação traria imediato subsídio, pois que a prova do corante em títulos inexpressivos, com prova de toxoplasmina negativa, observa-se exclusivamente nas 2 ou 3 primeiras semanas de doença ficando afastada a hipótese de infecção pregressa para explicar a positividade da reação. No presente inquérito não empregamos o teste cutâneo ou outras provas sorológicas auxiliares, como hemaglutinação ou fixação do complemento, preferindo estudar o comportamento sorológico relativo às provas do corante e imunofluorescência. Estas considerações, aliadas aos fatos observados na prática diária, apontam como melhor conduta, nos casos clìnicamente sugestivos, a obtenção de curva de títulos de uma das reações em aprêço, realizadas periòdicamente. É claro que o diagnóstico definitivo é fornecido pelo isolamento do toxoplasma na fase aguda ou sub aguda da infecção (SIIM ${ }^{25}$, 1956). Em relação ao comportamento sorológico observado em 21 alunos admitidos no ano seguinte ao do surto, os dados não foram concludentes no sentido de indicar, indiretamente, que êsses alunos estariam entrando em contato com uma fonte de infecção não identificada. $\mathbf{O}$ número de casos estudados sorològicamente foi pequeno, o tempo de observação deveria ser mais longo, não foi possível uma reavaliação clínica em todos êles e não houve referência a manifestações clínicas no período de 5 meses. Admite-se que certas intercorrências possam modificar a resposta imunobiológica em alguns indivíduos infectados, determinando pequenas variações do título sem expressão diagnóstica. REmington et aliii ${ }^{22}$ (1963) investigando a presença de anticorpos anti-toxoplasma entre colegiais, nos E.U.A., referem que um aumento significativo (mais do que $4 \mathrm{x}$ ) no nível de anticorpos pode ser explicado pela reex- posição ao antígeno ou por infecção aguda, não havendo ainda evidências da 1. hipótese, no ser humano. É possível que, em 3 seminaristas novos (F.C., L.B.P. e A.A.G.), os achados clínicos, ao $1 .^{\circ}$ exame, corressem por conta de toxoplasmose, só considerada provável à repetição das provas, 5 meses mais tarde.

Quanto aos aspectos epidemiológicos, salientam-se inicialmente, dois meios: a coletividade de estudantes e padres vivendo em comum, dentro de uma instituição e o ambiente rural, onde aquêles, eventualmente e os colonos repetidamente, entravam em contato com animais domésticos e artrópodes e cujas condições sanitárias eram más. Inúmeras são as possibilidades teóricas de contrair a toxoplasmose, nos meios acima referidos, desde que se admita serem o homem e os animais domésticos fontes potenciais de infecção (ArAUJo $^{2}$, 1964; Beattie ${ }^{5}$, 1960; Couvreur et alii ${ }^{9}, 1961$ ).

Quando a princípio se pensou estar o surto confinado ao Seminário pròpriamente dito, onde as condições de higiene eram satisfatórias, aventou-se a hipótese de contágio inter-humano, através de gotículas de Flügge. 0 primeiro isolamento do $T$. gondii, da saliva humana comunicado à literatura médica, deve-se a CATHIE (1954); entre nós LeVi et alii ${ }^{18}$ (1967) registraram o isolamento do protozoário da saliva em 9 dentre 10 pacientes com toxoplasmose, por inoculação intraperitoneal em camundongo. E interessante referir as conclusōes a que chegou W AAIJ $^{28}$ (1964) recentemente, após elaboração matemática dos dados obtidos em inquéritos sorológicos humanos realizados em 6 centros. De acôrdo com êsse autor, os cálculos matemáticos demonstraram a probabilidade de que a toxoplasmose seja uma infecção amplamente difundida, propagando-se de homem para homem por gotículas de Flügge, através de inalação. Esta hipótese, no entanto, não explicaria os casos verificados na fazenda do Seminário, motivo pelo qual não incluímos esta pesquisa na presente investigação. As- 
MAGALDI, C. et alii - Surto de toxoplasmose em um seminário de Bragança Paulista, SP. Aspectos clínicos, sorológicos. Rev. Saúde públ., S. Paulo, 1(2):141-171, dez. 1967.

sim, passamos a suspeitar também dos cães, dentre os quais 5 haviam apresentado doença nervosa e dos carneiros e ovelhas, antes de se conhecer a natureza da doença que estava dizimando o rebanho. As reações de Sabin-Feldman foram positivas em título nìtidamente mais elevados entre os cães do que entre os carneiros, ressaltando o resultado de 1:4000 obtido no cão "Duque", que pertencia ao caso $34 \mathrm{~B}$, com toxoplasmose comprovada e que, junto ao dono, convivia com as ovelhas. Estes dados vêm fortalecer a suspeita de que os cães constituíram fonte de infecção; infelizmente não houve oportunidade para autopsiar os animais mortos com "doença nervosa" e a inoculação de fezes de cães resultou negativa. Os carneiros sofriam de verminose maciça e uma autópsia feita não confirmou a suspeita de toxoplasmose. Além do mais, ainda são muito discutidas as relações entre achados positivos em inquéritos sorológicos de ovinos e a epidemiologia da toxoplasmose humana (JACobs, Remington, Melton 14, 1960). Restam outras hipóteses: ingestão de carne bovina ou de porco infectada com cistos e mal cozida, ingestão de águas poluídas e caldo de cana contaminado com fezes, contendo formas de resistência do toxoplasma e, finalmente, transmissão através de artrópodes vetores. Quanto à ingestão de carne bovina ou suína semi-crua, na literatura encontram-se referências à deglutição de cistos que resistiriam ao suco gástrico e infectariam o homem, por via oral (Desmonts et alii ${ }^{11}, 1965 ; J_{A}$ cobs, Remington, Melton ${ }^{14}, 1960$; Jamra, Deane, Guimarães ${ }^{15}$, 1966; WeINMAN \& ChandLER $\left.{ }^{30}, 1956\right)$. Lamentàvelmente, não tivemos facilidades e condiçôes para tentar o isolamento dos cistos a partir dos fragmentos de carne de vaca ou porco, obtida do matadouro do Seminário, não podendo por isso afastar definitivamente esta hipótese. $O$ inquérito sorológico entre suínos não trouxe nenhum subsídio, dado o pequeno número de animais examinados. A labilidade do toxoplasma, mesmo em sua forma cística, é bastante reco- nhecida, razão por que julgando ser difícil ou impossível sua sobrevivência em águas poluídas ou caldo de cana, não tentamos isolá-lo dêsses veículos líquidos. Segundo HARTLEY ${ }^{13}$ (1966), ainda são escassas as observaçōes sôbre a presença de cistos nos excreta de animais infectados e a possibilidade de que as excreçóes fossem infectadas e contaminassem a água nos pareceu muito remota. Deve ser lembrado, nesse sentido, que os alunos não faziam uso freqüente e sistemático de águas poluidas como os colonos. Em relação aos artrópodes vetores, como em outros ângulos da epidemiologia já abordados, o problema ainda está em aberto, longe de serem esgotadas as experimentações sôbre o tema. Beattie * (1959) não acha provável a transmissão através de artrópodes e Hartley ${ }^{13}$ (1966), revendo a epidemiologia da toxoplasmose, declara nunca ter sido demonstrada a multiplicaçáo do parasita no vetor, nem provada a transmissão por picada. O que ocorre, afirma êle, é a ingestão do toxoplasma por artrópodes hematófagos, observada experimentalmente, podendo o parasita sobreviver nestes por prazo não superior a 10 dias. Em nosso meio, NussenzweIG \& Deane ${ }^{20}$ (1958) provaram a possibilidade de transmissão mecânica dos toxoplasmas, por meio de picada de triatomíneos e DeANe ${ }^{10}$ (1958) relatou uma experiência em que foi inoculado o $T$. gondii por picada de carrapato Amblyomma cajennense, não podendo excluir, todavia, a probabilidade de contaminação por fezes ou líquido coxal do carrapato. Diante de dados mais ponderáveis entre os vários elementos de importância epidemiológica que entraram em nossas cogitações e que acabamos de discutir, consideramos dispensável, na ocasião, a pesquisa de infecção em artrópodes, nem mesmo nos preocupando com a identificação de reduvídeos e carrapatos mencionados pelos moradores do Seminário.

Em vista dos obstáculos inerentes à epidemiologia da toxoplasmose e das lacunas decorrentes de dificuldades de ordem téc- 
MAGALDI, C. et alii - Surto de toxoplasmose em um seminário de Bragança Paulista, SP. Aspectos clínicos, sorológicos.. Rev. Saúde públ., S. Paulo, 1(2):141-171, dez. 1967.

nica, chegamos ao final desta investigação sem nada conclúrmos ou comprovarmos a respeito das fontes de infecção ou das vias de transmissão, no presente surto de toxoplasmose. Acreditamos que, se contássemos com a oportunidade de isolar o agente etiológico da saliva humana, de tecidos de animais (principalmente cães doentes) e da carne bovina, obteríamos dados mais objetivos para confirmar uma ou mais hipóteses de trabalho. E como complementação, pesquisa de infecção em insetos, carrapatos e triatomíneos da área e ainda tentativa de isolamento a partir de líquidos e do solo contaminados por dejecções de animais. $\mathrm{Na}$ situação presente, secundando opiniảo de Beattie $^{3}$ (1957), é lícito também supor, que, mais do que um mecanismo de transmissão considerado pudesse estar em jôgo.

Uma vez assinalada a possibilidade de surtos de toxoplasmose em instituições fechadas ou em zona rural, insistimos na necessidade de investigações mais completas e profundas em situações similares, para o reconhecimento das fontes de infecção e mecanismos de transmissão, ainda que tais pesquisas sejam dificultadas pela carência de conhecimentos acêrca da história natural da toxoplasmose e do ciclo biológico do parasita.

\section{CONCLUSOES}

- A toxoplasmose (forma linfoglandular) foi diagnosticada, através de reação de Sabin-Feldman e de imunofluores. ciência indireto e de isolamento do $T$. gondii de gânglios linfáticos.

- $O$ estudo da evolução sorológica em 9 alunos desde o $33^{\circ}$ até o $140^{\circ}$ dia de doença, evidenciou em alguns casos, flu. tuações de títulos positivos no período e, em 2 casos, aparecimento tardío de anticorpos em diluições elevadas, compatíveis com doença em atividade.
- Os dados obtidos no estudo sorológico em 21 alunos novos, não concorreram para esclarecimento de hipóteses relativas à epidemiologia.

- Os dados e informações obtidos na inveștigação epidemiológica permitiram apenas aventar diversas hipóteses sôbre a transmissão, admitindo-se a possibilida. de de mais de um mecanismo em jôgo.

- A ocorrência de surto de toxoplas. mose é pela primeira vez relatada, na literatura médica. Em vista da problemática que envolve ainda a epidemiologia desta protozoose, em situações análogas torna-se absoluta a necessidade de investigações mais amplas e profundas, em torno da fontes de infecção e das vias de transmissão.

\section{S U M M A R Y}

Nine cases of comproved acquired toxoplasmosis (lymphatic form), from a Seminary in Bragança Paulista, (Brazil) motivated a clinical and serological survey. According to the data, at least 30 people (in a total of 81) presented, then, toxoplasmosis. Three hundred fourteen (314) dye-tests and indirect immunofluorescent tests were performed in all. The serological survey based on dye-test antibodies was extended to some local animal species. In view of the epidemiological survey limitations and notwithstanding the fact that a number of hipothesis have been suggested, no conclusions have been drawn, as far as the epidemiological aspects of the epidemics are concerned. Reporting this occurrence for the first time in the medical literature, the authors point out to the possibility of these outbreaks in closed institutions and in the rural area. They insist on the need for more complete researches, in similar situations, for the recognition of the sources and transmission mechanisms of the infection. Research work must be carried out in spite of the difficulties inherent to this subject. 
MAGALDI, C. et alii - Surto de toxoplasmose em um seminário de Bragança Paulista, SP. Aspectos clínicos, sorológicos. Rev. Saúde públ., S. Paulo, 1(2):141-171, dez. 1967.

\section{REFERENCIAS BIBLIOGRAFICAS}

1. AMATO NETO, V.; RIVETTI, F. S.; MALHEIROS JR., O. - Concomitância de casos de toxoplasmose adquirida, forma linfoglandular, em habitação coletiva da cidade de São Paulo. Rev. Inst. Med. trop., S. Paulo 9(2):73-78. mar/abr. 1967.

2. ARAUJO, F. C. - Contribuicão para o estudo da toxoplasmose em Portugal. Lisboa, 1964. (Tese de doutoramento - Faculdade de Medicina da Universidade de Lisboa).

3. BEATTIE, C. P. - Clinical and epidemiological aspects of toxoplasmosis. Trans. roy Soc. trop. Med. Hyg. 51 (1):96-103, Jan. 1957 .

4. The epidemiology of toxoplasmosis. In: HUMAN Toxoplasmosis: proceedings of the conference on clinical aspects and diagnostic problems of toxoplasmosis in paediatrics. Copenhagen, Munksgaard, 1959. p. 175.

5. Epidemiology of toxoplasmosis. Proc. roy. Soc. Med. 53(2):108111, Feb. 1960.

6. BEVERLEY, J. K. A. \& BEATTIE, C. P. - Glandular toxoplasmosis. A survey of 30 cases. Lancet $2(7043): 379$ 383, Aug. 1958.

7. CAMARGo, M. E. - Comparative evaluation of toxoplasmosis indirect fluorescent and Sabin-Feldman dye tests in a thousand human sera. A few unexpected results. Rev. Inst. Med. trop., S. Paulo 8(2):62-68, mar/abr. 1966.

8 CATHIE, I. A. B. - Toxoplasma adenopathy in a child with isolation of the parasite. Lancet $2(6829): 115-116$, jul. 1954.

9. COUVREUR, J. et. alii - Les modes de propagation de la toxoplasmose humaine. Remarques préliminaires. Arch. franc. Pédiat. 18(8):1026-1032, aôut, 1961.

10. DEANE, M. P. - Estudos sôbre a transmissão do Toxoplasma gondii. II. Nota sôbre a transmissão experimental pelo carrapato Amblyomma cajennense. Rev. bras. Malar. 10 (4) :551-555, out. 1958.
11. DEsMONTS, G. et alii - Etude épidémiologique sur la toxoplasmose: de l'influence de la cuisson des viandes de boucherie sur la fréquence de l'infection humaine. Rev. frang. Etud. clin. biol. 10:952-958, nov. 1965.

12. EICHENWALD, H. F. - The laboratory diagnosis of toxoplasmosis. Ann. $N$. Y. Acad. Sci. 64(2):207-214, jul. 1956.

13. HARTLEY, W. J. - A review of the epidemiology of toxoplasmosis. Med. $J$. A ust. 53-I (6) :232-235, Feb. 1966.

14. JACOBS, L.; REMINGTON, J. S.; MELTON, M. L. - A survey of meat samples from swine, cattle and sheep for the presence of encysted Toxoplasma. J. Parasit. 46(1):23-28, fev. 1960.

15. JAMRA, L. F.; DEANE, M. P.; GUIMARAES, E. C. - Isolamento do Toxoplasma gondii de amostras de carne de porco. Apresentado ao $73 .^{\circ}$ Seminário do Inst. Med. Trop. São Paulo, 8-9-1966. (Inédito).

16. JONES, F. E., et alii - A comparison of methods for the isolation of Toxoplasma from suspected hosts. Amer. J. trop. Med. Hyg. 7(5):531-535, Sept. 1958.

17. KELEN, A. E.; AYLLON-CLEINOL, L.; LABZOFFSKY, N. A. - Indirect fluorescent antibody method in serodiagnosis of toxoplasmosis. Canad. J. Microbiol. 8:545-554, 1962.

18. LEVI, G. C, et alii - Presença do Toxoplasma gondii na saliva de pacientes com toxoplasmose. Eventual importância dessa verificação quanto à transmissão da doença. Nota prévia. Apresentada ao 82.0 Seminário do Inst. Med. Trop. São Paulō, 17-8-1967. (Inédito).

19. NICHOLS, R. L. \& McCOMB, D. E. Immunofluorescent studies with trachoma and related antigens. $J$. Immunol. 89(4):545-554, Oct. 1962

20. NUSSENZWEIG, R. S. \& DEANE, M. P. - Estudos sôbre a transmissão do Toxoplasma gondii. I. Experiências com triatomineos. Rev, bras. Malar. $10(4): 543-550$, out. 1958. 
MAGALDI, C. et alii - Surto de toxoplasmose em um seminário de Braganca Paulista, SP. Aspectos clínicos, sorológicos.. Rev. Saúde públ., S. Paulo, 1(2):141-171, dez. 1967.

21. REMINGTON, J. S. et alii - Toxoplasmosis and infectlous mononucleosis. Arch. intern. Med. 110(5): 744-753, Nov., 1962.

22. among college students. New Engl. J. Med. 269(26):1394-1398, Dec. 1963.

23. SABIN, A. B. \& FELDMAN, H. A. Dyes as microchemical indications of a new immunity phenomenon affecting a protozoon parasite (Toxoplasma). Science, 108(2815):660-663, Dec. 1948.

24.

et alii - Present status of clinical manifestations of toxoplasmosis in man. Indications and provisions for routine serologic diagnosis. J.A.M.A. 150(11): 1063-1069, Nov. 1952.

25. SIIM, J. C. - Acquired toxoplasmosis. Report of seven cases with strongly positive serologic reactions. J.A.M.A. 147(17):1641-1645, Dec. 1951.
26. SIIM, J. C. - Toxoplasmosis acquisita lymphonodosa; clinical and pathological aspects. Ann. N. Y. Acad. Sci. 64(2) :185-206, Jul. 1956.

27. SINGH, I. et alij - Haemorrhagic disease following tick bites. Suspected toxoplasmosis. Lancet 1(7390):834838, Abr. 1965.

28. THALHAMMER, O. - Difficult and unsolved problems in the diagnosis of toxoplasmosis. In: HUMAN Toxoplasmosis: proceedings of the conference on clinical aspects and diagnosis problems of toxoplasmosis in paediatrics. Copenhagen, Munksgaard, 1959. p. 191.

29. WAAIJ, D. van der - The transmission of toxoplasmosis after birth. Trop. geogr. Med. 16(4):327-330, Dec. 1964.

30. WEINMAN, D. \& CHANDLER, A. H. Toxoplasmosis in man and swine an investigation of the possible relationship. J.A.M.A. 161(3): 229-232, May, 1956. 